\title{
Palmitoylated GLB1L4 transfers via exosomes to maintain sperm function in rat epididymis
}

\author{
Daqian Dong ${ }^{1,2,}{ }^{*}$, Jinmeng Yang ${ }^{1,4,}$, Yining Chen ${ }^{1}$, Guofan Peng ${ }^{1}$, Heran Cao ${ }^{1,2}$, Huihui Gao ${ }^{1,4}$, \\ Tianqi Jin ${ }^{1}$, Fangxia Yang ${ }^{3,4}$ and Wuzi Dong ${ }^{1,2}$ \\ ${ }^{1}$ College of Animal Science and Technology, Northwest A\&F University, Yangling, China, ${ }^{2}$ Shaanxi Provincial Key \\ Laboratory of Animal Genetics, Breeding and Reproduction, Northwest A\&F University, Yangling, China ${ }^{3}$ College of \\ Forestry, Northwest A\&F University, Yangling, China and 4 Shaanxi Stem Cell Engineering Research Center, \\ Northwest A\&F University, Yangling, China
}

Correspondence should be addressed to W Dong: dongwuzi@nwsuaf.edu.cn or to F Yang: yangfangxia@nwsuaf.edu.cn

*(D Dong and / Yang contributed equally to this study)

\begin{abstract}
Epididymal specific proteins play a crucial role in sperm maturation. Some of the post-translational modified proteins are transported from the caput to the cauda of the epididymis through exosomes which regulate the function of sperm in cauda epididymis. Rat beta-galactosidase-1-like protein 4 (GLB1L4) expressed specifically in the caput epididymis, localizes on the sperm; however, the regulatory ways in which GLB1L4 protein interacts with sperm to maintain sperm function are unclear. In this study, knockdown of rat GLB1L4 could inhibit in vitro capacitation of sperm in cauda epididymis and reduce the fertility of the male rats by injection of special lentivirus-shRNA into caput epididymis. Moreover, a considerable proportion of GLB1L4 proteins from rat caput epididymis were loaded on exosomes. The exosomes loaded GLB1L4 from in vitro primary rat caput epididymal epithelial cells could bind with spermatozoa in cauda epididymis. Further, the palmitoylation status of cysteine residues at the 12th and 15th sites of the protein molecule could significantly affect cellular localization of GLB1L4 protein. It was identified that most of GLB1L4 was palmitoylated in the presence of exosomes from primary caput epididymal cells and the level of palmitoylated GLB1L4 in the exosomes could be inhibited by 2-bromopalmitate (2-BP). These results suggested that the palmitoylated GLB1L4 from rat caput epididymis could be transported to the cauda epididymis to regulate the sperm function by exosomes.

Reproduction (2021) 161 159-172
\end{abstract}

\section{Introduction}

The immature spermatozoa from mammalian testis acquire motility and fertilizing ability in the epididymis which is a highly coiled duct that have important roles of maturation, concentration, protection, and storage of sperm (Zhu et al. 2007, Snyder et al. 2010). The spatial and temporal specificity of the epididymal gene expression is critical for its function maintenance and follows stringent regulation (Ellerbrock et al. 1994, Rodríguez et al. 2001). It had proved that in vivo RNAi could be an effective way to study certain gene function but transiently (Grillo et al. 2007, Frka et al. 2009, Towne \& Aebischer 2009, Chou et al. 2010). It can be more efficient to knockdown expression of the specific gene using shRNAs-lentiviral vector that produces the long-term and down-regulating effect in vivo and in vitro (Song et al. 2006, Grillo et al. 2007, Harper \& GonzalezAlegre 2008, Wang et al. 2008, 2009, Xie et al. 2008, Fan et al. 2014).
The epithelial cells in different epididymal segments can secret a large number of protein factors into the lumen to remodel sperm (Björkgren \& Sipilä 2019). Some proteins from epithelial cells are transferred in epididymis for long-distance via exosomes (namely epididymosomes), which is characterized by nanometerscale particle with phospholipid bilayer membrane (Zhou et al. 2018). It had been proved that the level of WNT2B protein was higher in the caput epididymis and the mature WNT2B was harbored in the exosomes from the epididymal lumen (Koch et al. 2015). Microphage migration inhibitory factor (MIF) in the epididymosomes is transferred to the intracellular dense fibers of the sperm flagellum to modulate sperm flagellar beating (Eickhoff et al. 2001). Both WNT2B and MIF were found to interact with sperm in mouse cauda epididymis, while they only expressed in mouse epididymal caput epithelial cells (Eickhoff et al. 2001, Koch et al. 2015).

Proteins are often subjected to a series of posttranslational modification (PTM) before being secreted 
Table 1 ShRNA stem-loop sequences and PCR primers.

\begin{tabular}{|c|c|c|}
\hline Items & Sequence $\left(5^{\prime}-3^{\prime}\right)$ & Aim \\
\hline shRNA-p1 & & $\begin{array}{l}\text { GLB1L4 interference } \\
\text { (Lv-p1) }\end{array}$ \\
\hline FC & GATCCGCACCAACTTTGGCTTAATTTCAAGAGATTAAGCCAAAGTTGGTGCTTTTTTG & \\
\hline RCC & AATTCAAAAAAGCACCAACTTTGGCTTAATCTCTTGAAATTAAGCCAAAGTTGGTGC & \\
\hline shRNA-p2 & & $\begin{array}{l}\text { GLB1L4 interference } \\
\text { (Lv-p2) }\end{array}$ \\
\hline FC & GATCCGGCGTAAAGATCCACTTCATTTTCAAGAGAATGAAGTGGATCTTTACGCCTTTTTTTG & \\
\hline RCC & AATTCAAAAAAGGCGTAAAGATCCACTTCATTCTCTTGAAAATGAAGTGGATCTTTACGCC & \\
\hline shRNA-g & & Control (Lv-g) \\
\hline FC & GATCCGGCGATGCCACCTACGGCAAGTTTTCAAGAGAACTTGCCGTAGGTGGCATCGCCTTTTTTG & \\
\hline RCC & AATTCAAAAAAGGCGATGCCACCTACGGCAAGTTCTCTTGAAAACTTGCCGTAGGTGGCATCGCC & \\
\hline GLB1L4 & & qPCR \\
\hline $\mathrm{F}$ & TGTTGATGAAGGATGTGCGTGAG & \\
\hline $\mathrm{R}$ & TGGTCGAGTGAGCGGGCTA & \\
\hline$\beta$-Actin & & qPCR \\
\hline $\mathrm{F}$ & AGACAGCCGCATCTTCTTGT & \\
\hline $\mathrm{R}$ & CTTGCCGGGGTAGAGTCAT & \\
\hline GLB1L4-12/15M & & $\begin{array}{l}\text { Primers for GLB1L4- } \\
\text { C12/15S mutant motif }\end{array}$ \\
\hline $\mathrm{F}$ & TGAAAGCATCСТGAGTCTGTCTTCAACСTTAGG & \\
\hline $\mathrm{R}$ & ACAGACTCAGGATGCTTTCAGGTCTCCCCAGGAAG & \\
\hline
\end{tabular}

The forward (FC) and reverse complimentary chains (RCC) and sequences ( $\mathrm{F}$ and $\mathrm{R}$ ) are presented.

from cells (Szabo-Taylor et al. 2015, Moreno-Gonzalo et al. 2018). S-palmitoylation modification of cysteine residue is a common and reversible modification to dynamically control the hydrophobicity which increases the lipid affinity of the protein molecule (María-Eugenia \& Gisou 2018). The modified proteins are led to localize in the endomembrane of cellular lipid bilayers (Dunphy \& Linder 1998, Percherancier et al. 2001, Lanyon-Hogg et al. 2017, Jiang et al. 2018). And the S-palmitoylation proteins may be preferentially selected into the extracellular vesicles which are released outside of cells (Yang et al. 2010, Shen et al. 2011, Verweij et al. 2015, Shibata et al. 2017, Romancino et al. 2018).

Beta-galactosidase 1-like 4 gene $(\mathrm{G} / \mathrm{b} 1 / 4)$ is specifically expressed in the epithelial cells of rat caput epididymis, and the GLB1L4 can be secreted into the luminal fluid and bound on the sperm (Zhen et al. 2009). But it is unclear how the GLB1L4 protein regulates sperm maturation in epididymis. In this study, GLB1L4 function would be explored through in vivo knockdown expression of GLB1L4 by microinjection of the special shRNAs-lentivirus into rat caput epididymis. Further, post-translational modification state of GLB1L4 would be analyzed to resolve the potential relationship between GLB1L4 and sperm maturation in rat epididymis.

\section{Materials and methods}

\section{Animals}

Animals (Sprague-Dawley rats) were purchased from The Animal Center of the Chinese Academy of Sciences (Shanghai, China) and The Animal Center of Xi'an Jiaotong University (Xi'an, China). They were housed for an additional 7-10 days before manipulation. Food and water were freely available throughout the experiments. In the study, the experiments were conducted according to a protocol approved by the Animal Care Committee of Northwest A\&F University (NWAFUACC-2018-2).

\section{Reconstruction and transfection of pcDNA3.1-Wt- GLB1L4 (WT) and pcDNA3.1-Mut-GLB1L4 (C12/15S)}

The pcDNA3.1-GLB1L4-Wt is a eukaryotic expression plasmid with the full-length sequence of rat GLB1L4 cDNA reconstructed previously. In order to obtain the mutant GLB1L4 protein whose 12th and 15th cysteine residues were changed to serine, the pcDNA3.1-Mut-GLB1L4 (C12/15S) plasmid was generated by site-directed mutagenesis using Hieff MutTM Site-Directed Mutagenesis Kit (Qcbio Science \& Technologies Co., Ltd, Item No 11003ES10) according to the instructions of the manufacturer (the mutational primers are shown in Table 1, forward primer: GLB1L4-C12/15S-M-F, reverse primer: GLB1L4-C12/15S-M-R).

PC1 cell line of mouse caput epididymis was provided by Prof Orgebin-Crist lab (the Center for Reproductive Biology Research, Tohoku University, Sendai 980-8575, Japan) and cultured in a plastic culture plate supplemented with Iscove's modified Dulbecco's medium (IMDM) containing 10\% fetal calf serum (FCS) at $32^{\circ} \mathrm{C}$ as described previously (Araki et al. 2002, Mühlbauer et al. 2008). The pcDNA3.1-Wt-GLB1L4 and the pcDNA3.1-Mut-GLB1L4 (C12/15S) were transfected into PC1 cells by lipofectamine (Invitrogen), respectively.

\section{Production of ShRNA-lentivirus}

Stem-loop of ShRNA double strands of GLB1L4 (ShRNA-p1 and ShRNA-p2) and EGFP (ShRNA-g) were cloned into the pLVEGFP-C lentiviral vector (Inovogen Tech. Co., Cat. No. VL3101). The lentiviral particles were produced by co-transfection of lentiviral vector (including Lenti/ShRNA-p1, Lenti/ShRNA-p2 and Lenti/ShRNA-g), the packaging plasmids $\mathrm{pH} 1$ and $\mathrm{pH} 2$ 
into 293T cells, using the lipofectamine 2000 (invitrogen). And then the lentivirus (Lv-p1, Lv-p2 and Lv-g) was harvested after 48-72 $\mathrm{h}$ and concentrated by ultracentrifugation (100,000 g). The virus titer (Unit titer, UT/mL) was determined via quantification of the EGFP fluorescence intensity of 293T cells by flow cytometry according to previous report (Du et al. 2016). Stem-loop of ShRNA double strands of GLB1L4 (shRNA-p1 and shRNA-p2) and EGFP (shRNA-g) were shown in Table 1.

$1 \times 10^{6} \mathrm{UT} / \mathrm{mL}$ viruses (Lv-p1, Lv-p2 and Lv-g) infected the PC1 cells in six wells plate, respectively. The knockdown efficiency of GLB1L4 RNA and protein were determined by qPCR and Western blot at $48 \mathrm{~h}$ after infection, respectively.

\section{Injection of lentivirus into rat caput epididymis}

The rats were anesthetized with pentobarbital sodium (40 mg/ $\mathrm{kg}$ body weight). After opening the abdominal cavity of the rat with scissors, the epididymis was exposed. In total, $50 \mu \mathrm{L}$ (total units titer about $2 \times 10^{6}$ ) shRNA-lentivirus (Lv-p1 or Lv-g) was injected into the stroma of caput epididymis of 60-day-old rats until the caput displayed trypan blue (TB) (Sigma) via a sharpened glass microcapillary pipette (GC100T-10, Harvard apparatus LTD Fircroft way, Edenbridge, Kent, TN86HE), respectively. Experiment 1: As an experimental group, the right epididymis of rat was injected with Lv-p1, while as a control, the left epididymis of the rat was injected with Lv-g. There were three rats in every test and each experiment was repeated three times. Experiment 2: For mating test, eight rats were injected with Lv-p1 or Lv-g into the bilateral epididymis, respectively. 30 days after injection, each male mated with two normal females.

\section{Evaluation of sperm capacitation}

To assess capacitation, sperm from the cauda epididymis was released into the semen diluent $(94.6 \mathrm{mM} \mathrm{NaCl}, 1.19$ $\mathrm{mM} \mathrm{KH} \mathrm{PO}_{4}, 25 \mathrm{mM} \mathrm{NaHCO}, 5.56 \mathrm{mM}$ glucose, 10.76 $\mathrm{mM}$ sodium lactate and $0.5 \mathrm{mM}$ sodium pyruvate, $50 \mathrm{mg} /$ $\mathrm{mL}$ streptomycin sulfate, $75 \mathrm{mg} / \mathrm{mL}$ potassium penicillin, $\mathrm{pH}$ 7.4, osmolarity about $310 \mathrm{mOs} \mathrm{mol} / \mathrm{kg}$ ). After centrifugation at $800 \mathrm{~g}$ for $5 \mathrm{~min}$, sperm was resuspended in the capacitation medium (diluent with $1.71 \mathrm{mM} \mathrm{CaCl}_{2}, 1.19 \mathrm{mM} \mathrm{MgSO}_{4}, 4$ $\mathrm{mg} / \mathrm{mL} \mathrm{BSA}$ ) and the sperm was incubated for $3 \mathrm{~h}$ at $37^{\circ} \mathrm{C}$. The time-point of spermatozoa dilution was defined as the beginning of capacitation $(0 \mathrm{~h})$. The sperm pellets were suspended in RIPA with $0.1 \%$ SDS sample buffer, and total sperm protein was performed on PAGE with $12 \%$ Tris-glycine gels. The tyrosine phosphorylation of spermatozoa protein was detected by Western blot.

\section{Sperm motility analysis}

Sperm motility was analyzed according to a previous method (Zhou et al. 2008). Suspensions of spermatozoa were loaded into flat $100 \mu \mathrm{m}$ deep microslides (HTR1099, VitroCom Inc., Mt. Lks. NJ, USA) for CASA analysis using HTM-TOXIVOS sperm motility analyzer (Rat Head Toxicology, version 12.3A, Hamilton-Thorn Research, MA, USA). Instrument settings were: temperature, $37^{\circ} \mathrm{C}$; low VAP cut-off, 20.0; low VSL cut-off, 30.0; threshold straightness, 50\%; static head size, 0.72-8.82; static head intensity, 0.14-1.84. In total, 30 frames were acquired at a frame rate of $60 \mathrm{~Hz}$. During analysis, the playback feature was used to check its accuracy.

\section{Fertility assay}

30 days after injection with the same lentivirus into bilateral epididymis, male rats mated with normal female rats. They were maintained together overnight, and vaginal smears of the females were taken the next morning and examined by microscopy. The female rats were successfully mated if spermatozoa were present in vaginal smears. The mated male rats were sampled to determine the knockdown efficiency of GLB1L4. Then pregnant females that mated with the GLB1L4 knockdown male rats were housed individually. The pregnant females were subjected to hysterectomy to determine the number of fetuses.

\section{Separation and culture of epithelial cells from rat caput epididymis}

After the adult male rats (60 days old) were killed, the epididymis was removed from the rat abdominal cavity and immersed in $75 \%$ ethyl alcohol, brought into the cell culture lab immediately. After the white membrane of the epididymis was removed, the caput epididymis was cut into pieces using eye scissors in sterile PBS with penicillin and streptomycin. To remove sperm, the tissues were washed three to four times until PBS buffer was not turbid. For tubule isolation, tissue fragments were treated for $30 \mathrm{~min}$ at room temperature in the IMDM (Iscove's Modified Dubecco's Medium) supplemented with the antibiotics and $2 \mathrm{mg} / \mathrm{mL}$ IV type collagenase (Invitrogen) and $20 \mathrm{U} / \mathrm{mL}$ DNase I (Promega). After small pieces of tissue were collected by gravity sediment, the pellets were digested for $4 \mathrm{~min}$ in $0.125 \%$ trypsin-EDTA (Gibco) and filtrated to remove bulk tissues through $70 \mu \mathrm{m}$ nylon membrane filters. Finally, the cells were collected by centrifugation at $450 \mathrm{~g}$ for $5 \mathrm{~min}$, washed, and suspended in serum-free IMDM medium (v/v) (Gibco) supplemented with the following nutrients and growth factors: $50 \mathrm{U} / \mathrm{mL}$ penicillin, $50 \mu \mathrm{g} / \mathrm{mL}$ streptomycin, $2 \mathrm{mmol} / \mathrm{L}$ glutamine, 10 $\mu \mathrm{g} / \mathrm{mL}$ insulin, $10 \mu \mathrm{g} / \mathrm{mL}$ transferrin, L-carnitine $(1 \mathrm{mM}), 1 \mu \mathrm{g} /$ $\mathrm{mL}$ retinoic acid, $10 \mathrm{ng} / \mathrm{mL}$ EGF, $10 \mathrm{ng} / \mathrm{mL}$ cholera toxin, 10 $\mathrm{nM}$ hydrocortisone, $100 \mathrm{nM}$ double hydrogen testosterone. The cells were then placed in $60 \mathrm{~mm}$ petri dish and incubated in a humidified chamber at $32^{\circ} \mathrm{C}$ with $5 \% \mathrm{CO}_{2}$. After $1 \mathrm{~h}$, the unattached cells were moved to a new petri dish. To further remove fibroblasts, the cells were digested with $0.05 \%$ trypsin for $1 \mathrm{~min}$ after being cultured for $24 \mathrm{~h}$, and the attached cells were continually cultured in whole medium, while the unattached cells (fibroblasts) were removed (Wang et al. 2010). The culture medium was changed every $48 \mathrm{~h}$. The epithelial cells were digested using $0.25 \%$ trypsin to amplify sub-culturing cells. Identification of epididymal epithelial cells (>95\%) was assessed using CK18 protein antibody (Sigma, No C1399, 1:200) by immunofluorescence. 
A

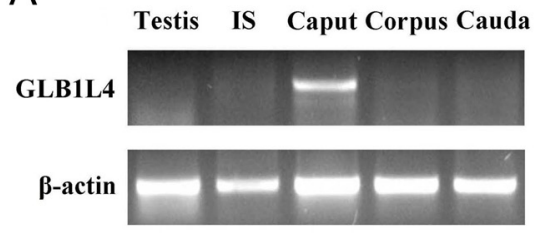

B

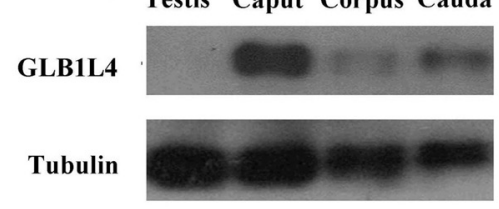

C

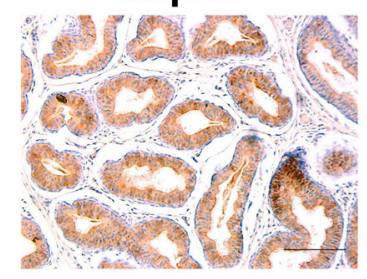

D

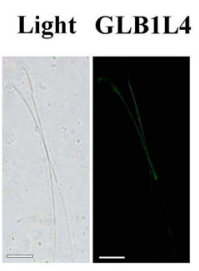

Corpus

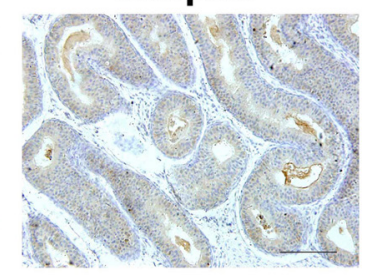

E

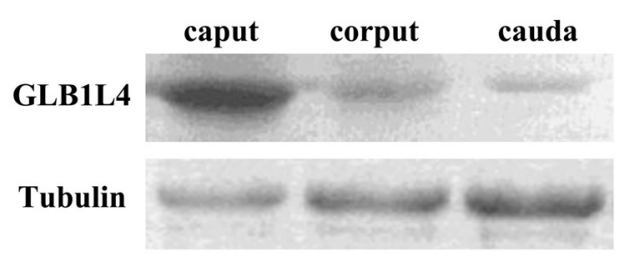

Cauda

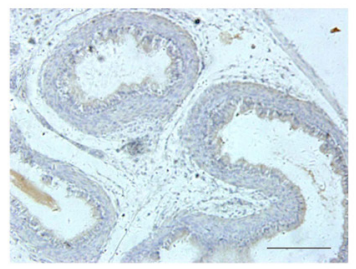

Figure 1 Specific expression of rat GLB1L4 in the caput epididymis. (A) The G/b1/4 mRNA specific expression in the caput epididymis of rat by RT-PCR; (B) The GLB1L4 protein in caput, corpus and cauda epididymis by Western blot. (C) The immunolocalization of rat GLB1L4 protein in the epididymis tissues of 90-day-old male rat. Scale size: $100 \mu \mathrm{m}$. (D) The GLB1L4 protein location on sperm in cauda epididymis by immunofluorescent staining. (E) The GLB1L4 protein expression of sperm in caput, corpus and cauda epididymis by Western blot. caput, corpus and cauda represented sperm protein of caput, corpus and cauda, respectively.

\section{Isolation and characterization of exosomes}

Isolation of exosomes from the epididymal lumen fluid and primary epididymal epithelial cells

To isolate the exosomes from epididymal lumen fluid, a previous method was used with slight modifications in this study (Zhen et al. 2009, Koch et al. 2015). Briefly, ten epididymal tissues from five adult rats were used per test in a tube. To avoid contamination of the damaged epididymal epithelial cell components, each epididymis was cut into pieces carefully using eye scissors, and then the ten epididymal tissues were immersed in $50 \mathrm{~mL}$ PBS. The tube was shaken gently for $4 \mathrm{~h}$ in a shaker at $4^{\circ} \mathrm{C}$. After the lumen fluid was fully discharged, the samples were centrifuged at $2000 \mathrm{~g}$ for $15 \mathrm{~min}$ at $4^{\circ} \mathrm{C}$ to remove the tissue and cell debris. The supernatant was centrifuged at $5000 \mathrm{~g}$ for $15 \mathrm{~min}$ at $4^{\circ} \mathrm{C}$ to remove smaller cell debris. The supernatant was used to prepare the epididymal lumen-derived exosomes.

In like manner, the media was centrifuged at $2000 \mathrm{~g}$ for 15 min at $4^{\circ} \mathrm{C}$ to remove the cell debris after the epididymal epithelial cells were cultured for $72 \mathrm{~h}$ in vitro. The supernatant was then collected after centrifugation at $5000 \mathrm{~g}$ for $15 \mathrm{~min}$ at $4^{\circ} \mathrm{C}$. The supernatant was used to isolate the epididymal epithelial cell-derived exosomes.

Exosomes were isolated from the supernatant of the primary epithelial cells from caput epididymis or epididymal lumen fluid by gradient ultracentrifugation according to a previously described method with modifications (Gao et al. 2018). In each experiment, at least $50 \mathrm{~mL}$ of the supernatant was centrifuged at $16,000 \mathrm{~g}$ for $15 \mathrm{~min}$ at $4^{\circ} \mathrm{C}$ to remove pellets. The supernatant was filtered using $0.22 \mu \mathrm{m}$ filters, and the exosomes were collected by centrifugation at 120,000 $\boldsymbol{g}$ for 1 $\mathrm{h}$ at $4^{\circ} \mathrm{C}$. The pellets were then washed twice with buffer (30 $\mathrm{mM}$ Tris, $130 \mathrm{mM} \mathrm{NaCl}, \mathrm{pH}$ 7.6) followed by centrifugation at $120,000 \mathrm{~g}$ for $1 \mathrm{~h}$ at $4^{\circ} \mathrm{C}$. Finally, the exosome pellets were resuspended in $0.5 \mathrm{~mL}$ sterile PBS.

\section{Detection of exosomes}

The exosome suspension was diluted 1000 times in the PBS. The particle size of exosomes were observed and the concentration (particles $/ \mathrm{mL}$ ) of exosomes was calculated with the NanoSight NS3000 system according to the manufacturer's protocols (Malvern Instruments, Malvern, UK). The profile of the exosomes were observed by Scan electron microscopy using previously described methods (Gao et al. 2018).

\section{PKH67 labeling of exosomes}

Exosomes from primary epididymal epithelial cells were resuspended in PBS and PKH67 (the final concentration is $0.01 \mathrm{mM}$ ) was added, and then the solution was incubated for $10 \mathrm{~min}$ at $37^{\circ} \mathrm{C}$. Excess dye was removed by centrifugation at $120,000 \mathrm{~g}$ for $1 \mathrm{~h}$ at $4^{\circ} \mathrm{C}$ and the PKH67-labeled exosomes were resuspended with $0.5 \mathrm{~mL}$ semen diluent.

\section{Test of exosomes binding sperm}

Sperm collected from cauda epididymis was washed three times using the semen diluent and resuspended with $90 \mu \mathrm{L}$ semen diluent. Then $10 \mu \mathrm{L}$ PKH67-labeled exosomes were added into the solution for $1 \mathrm{~h}$ at $37^{\circ} \mathrm{C}$. Finally, the sperm was washed three times in PBS and then dropped on slides and observed in fluorescence microscope. 


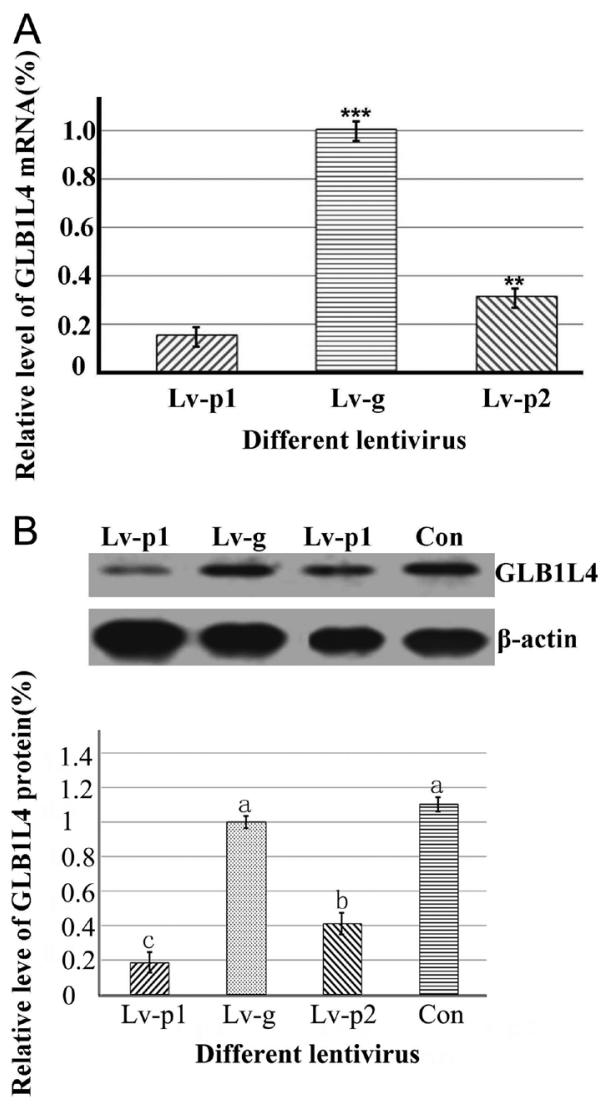

Figure 2 Detection of GLB1L4 knockdown in vitro. (A) Expression level of Glb1/4 mRNA after infection of viruses (Lv-p1, Lv-p2 and Lv-g) into the PC1 cell overexpressing GLB1L4 by RT-qPCR $(n=3)$. (B) Expression level of GLB1L4 protein after infection of viruses (Lv-p1, Lv-p2 and Lv-g) into the PC1 cell overexpressing GLB1L4 by Western blot $(n=3)$. Lv-p1, Lv-p2 and Lv-g represented the samples from the overexpressing GLB1L4 PC1 cell that had been treated with Lv-p1, Lv-p2 and Lv-g lentiviral, respectively. Con represented samples from the overexpressing GLB1L4 PC1 cell that had not been treated with any lentiviral vectors. a, b, c: The same letter means no significant difference, while the difference between different letters is significant.

\section{Effect of 2-BP on the epididymal epithelial cells}

To analyze effect of 2-BP on protein palmitoylation, the epididymal epithelial cells were cultured for $24 \mathrm{~h}$ in the whole serum-free medium with final concentration of $20 \mathrm{mM}$ 2-BP (without 2-BP as control). The cells were observed under a microscope, and then protein of cells, the medium and exosomes from the cells were extracted for Western blot and ABE assay.

\section{Extraction of the palmitoylated proteins of cells using acyl-biotinyl exchange (ABE) method}

The ABE assay for determination of the palmitoylation level was carried out as described previously (Wan et al. 2007). Briefly, after incubating with N-ethylmaleimide (NEM, Thermo) to block free sulfhydryl groups on proteins, purified samples were treated with or without hydroxylamine (HA, Thermo)
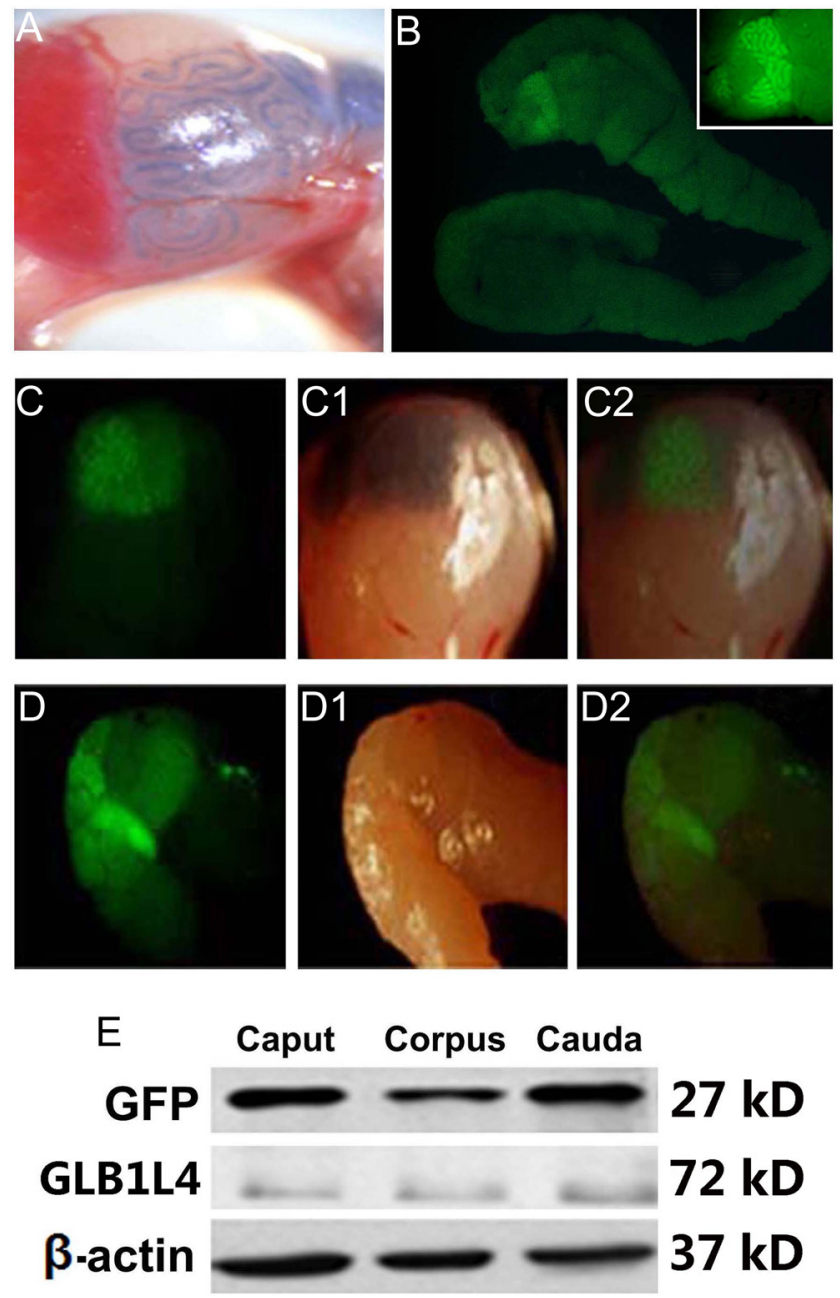

Figure 3 Observation of lentivirus injected into rat caput epididymis. (A) The virus solution with trypan blue (TB) was distributed in rat caput epididymis when $50 \mu \mathrm{L}$ virus was injected into rat caput epididymis. (B) The green fluorescence in rat caput epididymis was observed by fluorescence stereoscopy on the second day after the virus was injected. (C and D) The green fluorescence in rat caput (C) and cauda (D) epididymis was detected by fluorescence stereoscopy on the 30th day after the virus was injected into epididymis. (E) Expression of EGFP and GLB1L4 in caput, corpus and cauda epididymis was analyzed by Western blot.

and Biotin-BMCC (Thermo) to label palmitoylation sites. The presence of Biotin on proteins was then analyzed by SDSPAGE with HRP-conjugated anti-streptavidin (Beyotime). The detailed protocol of $\mathrm{ABE}$ is described subsequently.

\section{Sealing the protein - SH using NEM}

A total of $300 \mu \mathrm{L}$ of SDS buffer (4\% SDS, $50 \mathrm{mM}$ Tris, $\mathrm{pH}$ 7.4 and $5 \mathrm{mM}$ EDTA) containing $10 \mathrm{mM}$ NEM was added to the samples (medium, cells or exosomes) and the mixture was incubated for $10 \mathrm{~min}$ at $37^{\circ} \mathrm{C}$ with occasional agitation to lysis the samples. Then $900 \mu \mathrm{L}$ of buffer $(50 \mathrm{mM}$ Tris- $\mathrm{HCl}, \mathrm{pH} 7.4$, $150 \mathrm{mM} \mathrm{NaCl}, 5 \mathrm{mM}$ EDTA, 1 mM NEM, 0.2\% Triton X-100, 
$1 \mathrm{mM}$ phenylmethylsulfonyl fluoride (PMSF) and $0.25 \mu \mathrm{g} / \mathrm{mL}$ each of pepstatin, leupeptin, antipain and chymostatin) was added to the sample solution and the mixture was incubated overnight at $4{ }^{\circ} \mathrm{C}$ with gentle rocking. Unreacted NEM was removed by three sequential precipitations with ice-cold acetone as described previously.

\section{Reduction of fatty acyl groups}

The protein pellet was collected by centrifugation $(10,000 \mathrm{~g}, 10$ min), dissolved in $240 \mu \mathrm{L}$ of SDS buffer (4\% SDS, $50 \mathrm{mM}$ Tris, $\mathrm{pH} 7.4$ and $5 \mathrm{mM}$ EDTA) and incubated at $37^{\circ} \mathrm{C}$ for $10 \mathrm{~min}$. At this point, the sample was divided into two equal portions, one with $\mathrm{HA}(+\mathrm{HA}$ sample) and the other without HA (-HA sample) in $1.5 \mathrm{~mL}$ screw-cap centrifuge tubes. The $+\mathrm{HA}$ sample was diluted five-fold with $480 \mu \mathrm{L}$ of the $+\mathrm{HA}$ buffer. For the $-\mathrm{HA}$ sample, $480 \mu \mathrm{L}$ of $-\mathrm{HA}$ buffer was used. +HA buffer: $0.7 \mathrm{M}$ hydroxylamine, $\mathrm{pH} 7.4,1 \mathrm{mM}$ HPDP-biotin, $0.2 \%$ Triton X-100, $1 \mathrm{mM}$ PMSF and $0.25 \mu \mathrm{g} / \mathrm{mL}$ each of pepstatin, leupeptin, antipain and chymostatin. - HA buffer: $50 \mathrm{mM}$ Tris- $\mathrm{HCl}, \mathrm{pH} 7.4$, $1 \mathrm{mM}$ HPDP-biotin, 0.2\% Triton X-100, $1 \mathrm{mM}$ PMSF and 0.25 $\mu \mathrm{g} / \mathrm{mL}$ each of pepstatin, leupeptin, antipain and chymostatin.

\section{HPDP-biotin sign}

The two sample solutions were incubated at room temperature for $1 \mathrm{~h}$ with end-over-end rotation. After the reaction, the tubulin was precipitated three times using ice-cold acetone. Each resulting pellet was dissolved in $120 \mu \mathrm{L}$ of SDS buffer (4\% SDS, $50 \mathrm{mM}$ Tris, pH 7.4 and $5 \mathrm{mM}$ EDTA), diluted with $480 \mu \mathrm{L}$ of low-HPDP-biotin buffer (50 mM Tris-HCl, $\mathrm{pH} 7.4$, $150 \mathrm{mM} \mathrm{NaCl}, 5 \mathrm{mM}$ EDTA, $0.2 \mathrm{mM}$ HPDP-biotin, $0.2 \%$ Triton X-100, $1 \mathrm{mM}$ PMSF and $0.25 \mu \mathrm{g} / \mathrm{mL}$ each of pepstatin, leupeptin, antipain and chymostatin) and then incubated at room temperature for $1 \mathrm{~h}$ with end-over-end rotation. To remove unreacted HPDP-biotin, both samples were precipitated three times using ice-cold acetone. Each pellet was dissolved in 1.5 $\mathrm{mL}$ of incubation buffer (50 mM Tris- $\mathrm{HCl}, \mathrm{pH} 7.7,1 \mathrm{mM}$ EDTA and $0.4 \%$ Triton $\mathrm{X}-100)$. Twenty micrograms of sequencing grade modified trypsin were added to each sample solution and incubated at $37^{\circ} \mathrm{C}$ overnight. To terminate proteolysis, PMSF was added to a final concentration of $1 \mathrm{mM}$.

\section{Isolation of HPDP-biotinylated peptides}

To perform affinity purification of the HPDP-biotinylated peptides from the digested tubulin, $0.5 \mathrm{~mL}$ of $50 \%$ suspension of streptavidin agarose was washed twice by resuspension in 5 $\mathrm{mL}$ of ice-cold PBS buffer (0.1 M phosphate, $\mathrm{pH} 7.2$ and 0.15 $\mathrm{M} \mathrm{NaCl}$ ), followed by gravity sedimentation and decanting the supernatant. The washed streptavidin beads were resuspended in $0.25 \mathrm{~mL}$ of incubation buffer. To affinity-capture the HPDPbiotinylated peptides, $100 \mu \mathrm{L}$ of the streptavidin agarose bead suspension was added to each tryptic digest. The mixture was incubated at room temperature with rotation. After $1 \mathrm{~h}$, the beads were pelleted by centrifugation at $2000 \mathrm{~g}$ for $10 \mathrm{~min}$ and washed four times each with incubation buffer, wash buffer (50 mM Tris- $\mathrm{HCl}$, pH 7.7, $600 \mathrm{mM} \mathrm{NaCl}, 1 \mathrm{mM}$ EDTA and $0.4 \%$ Triton X-100) and bicarbonate buffer (5 mM ammonium bicarbonate in $20 \%$ acetonitrile). HPDP-biotinylated peptides were eluted from streptavidin agarose by incubation with 500 $\mu \mathrm{L}$ of Mguanidine hydrochloride $(\mathrm{pH} 1.5)$ for $30 \mathrm{~min}$ with gentle inversion at room temperature. Sample solutions were centrifuged to remove insoluble particulates. The supernatants were collected for the following studies.

\section{Immunohistochemistry (IHC)}

For histological analysis, epididymal tissues were fixed in Bouin's fixative overnight. After successive dehydration, the tissues were imbedded in paraffin. Sections were mounted on slides with poly-lysine pretreatment, dewaxed in a xylene bath, and then rehydrated through gradient ethanol solutions. The sections were used for IHC. After rinsing in PBS, the slides were placed in boiling citrate for heat-mediated antigen retrieval for $10 \mathrm{~min}$. Slides were cooled for $40 \mathrm{~min}$ at room temperature and then rinsed three times with PBS before being treated with $3 \% \mathrm{H}_{2} \mathrm{O}_{2}$. Non-specific protein binding was blocked for $1 \mathrm{~h}$ by normal goat

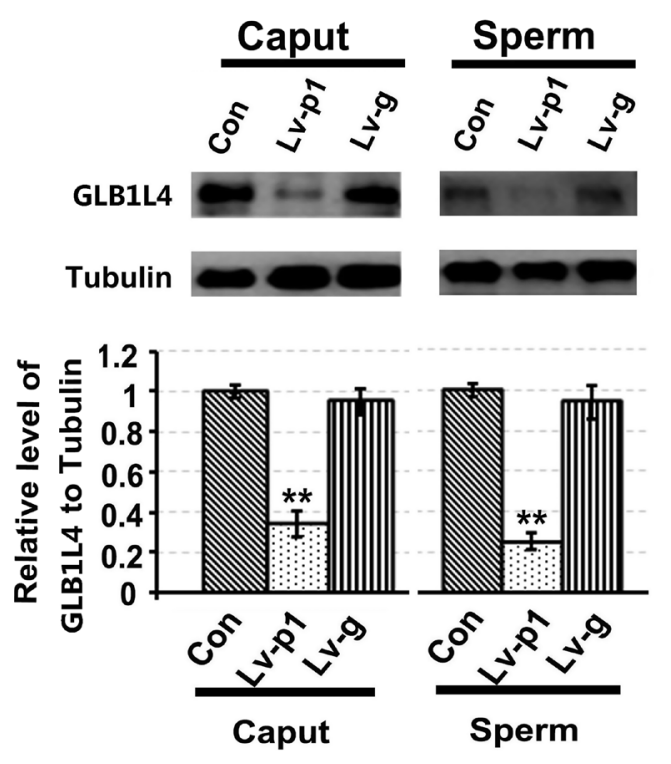

Reproduction (2021) 161 159-172

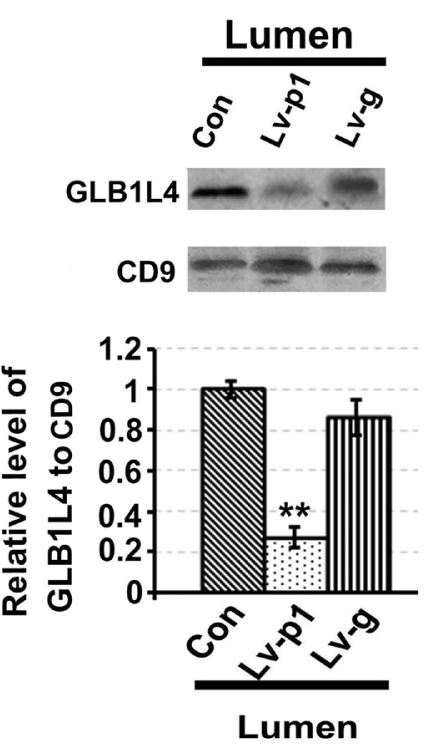

Figure 4 Detection of the expression level of GLB1L4 protein in the caput epididymis, lumen of epididymis and sperm on the 30th day after lentivirus (Lv-p1 and Lv-g) was injected into rat caput epididymis by Western blot $(n=3)$. 

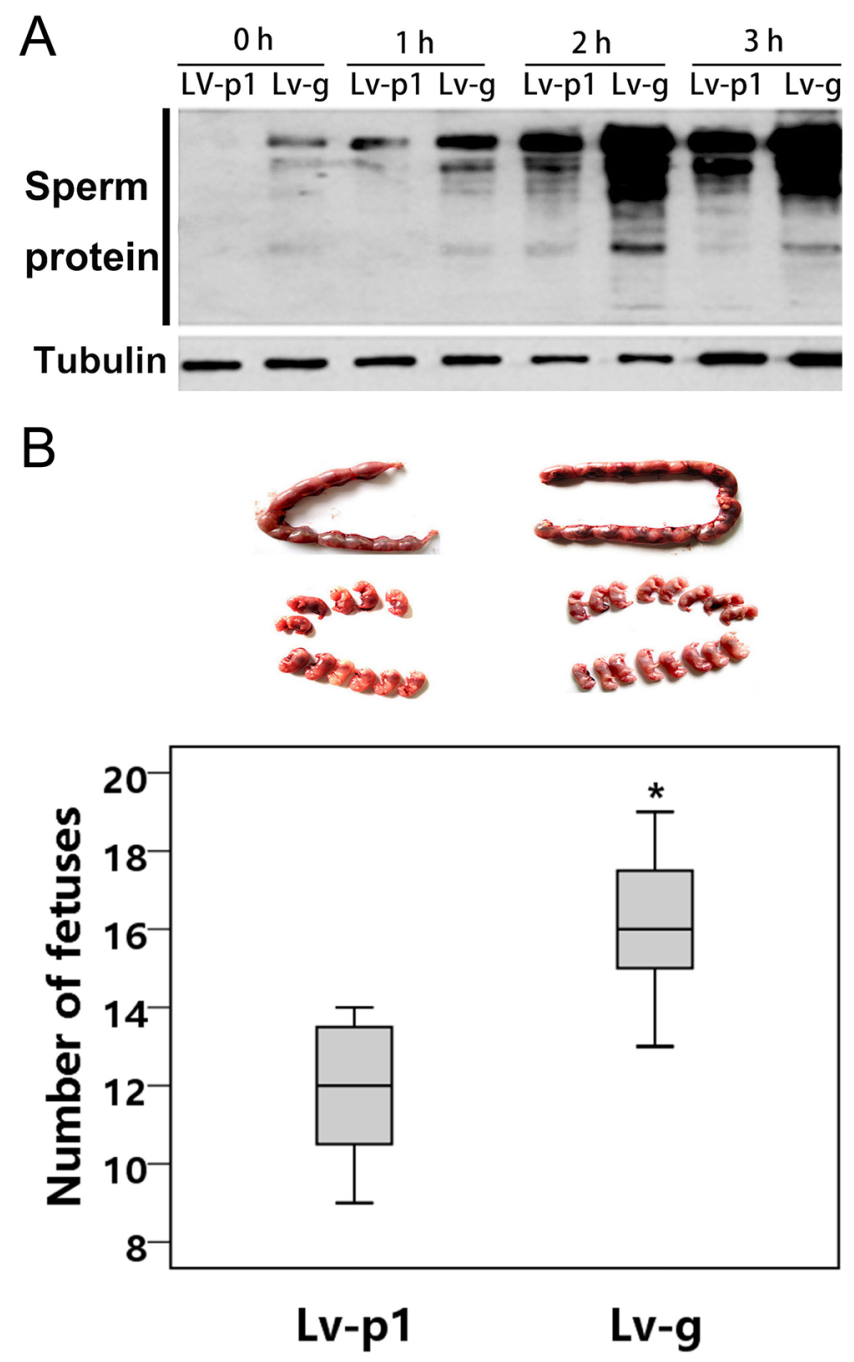

Figure 5 Influence of knockdown expression of GLB1L4 protein on sperm capacitation and male fertility. (A) The tyrosine phosphorylation of sperm proteins was analyzed by induction of sperm capacitation in vitro with $\mathrm{BSA}$ and $\mathrm{Ca}^{2+}$, the semen samples were from the cauda epididymis of the male rats which was injected with the Lv-p1 lentivirus into bilateral caput epididymis for 30 days. (B) The average number of fetuses of female rats mated with the GLB1L4 knockdown male rats with same lentivirus (Lv-p1 or Lv-g) injected into bilateral epididymis.

serum before incubating with the GLB1L4 antibody (Zhen et al. 2009, 1:200) overnight in a damp box. Sections were washed with PBS and incubated for 30 min with biotinylated anti-rabbit IgG (Solarbio, SHB134, 1:100). Tissues slides were stained by diaminobenzidine (DAB) according to the manufacturer's instructions before counterstaining with hematoxylin. Images were obtained using a microscope (Carl Zeiss Company Ltd). As controls, the primary antibodies were replaced by PBS.

\section{Immunofluorescence}

For immunostaining, the cells were cultured in 48-well plate at $32^{\circ} \mathrm{C}$ for $24 \mathrm{~h}$, fixed in $4 \%$ paraformaldehyde for $15 \mathrm{~min}$. The fixed cells were then treated with PBS (pH 7.2) containing
$0.3 \%(\mathrm{v} / \mathrm{v})$ Triton $\mathrm{X}-100$ for $10 \mathrm{~min}$ at room temperature. The blocking of non-specific antigens was incubated with $10 \%$ $(\mathrm{w} / \mathrm{v})$ goat serum in $\mathrm{PBS}$ for $1 \mathrm{~h}$ at $37^{\circ} \mathrm{C}$. Then the cytokeratin-18 (CK-18) antibody mouse MAB (Sigma, No C1399, 1:200) was performed for $12 \mathrm{~h}$ at $4{ }^{\circ} \mathrm{C}$. The secondary antibody employed was fluorescein isothiocyanate (FITC)-goat anti-mouse IgG (sino-American Biotechnology Co., Luoyang, 1:300). The nuclear was stained with DAPI (Sigma, cat. no. D9542, 1:1000). Control cells received the same treatment except that the primary antibody was replaced with PBS. Immunofluorescencestained samples were examined with Axiophot microscope equipped fluorescence (Carl Zeiss Company Ltd). Images were captured with a CCD camera using SPOT RT software version 3.1 (Diagnostic Instruments Inc, Sterling Heights, Mich) and then edited with Adobe Photoshop 6.0.

\section{RNA Isolation and PCR}

Total RNA of different samples was isolated with Trizol reagent (Invitrogen) following the manufacturer's recommendations. Total RNA isolated was reverse transcribed using an oligo dT (20) primer by M-MLV Reverse Transcriptase (Promega) according to the manufacturer's recommendations.

PCR was subsequently done to identify the presence of transcriptional GLB 1L4. PCR amplification was done using the following program: $94^{\circ} \mathrm{C}$ for $5 \mathrm{~min}, 35$ cycles of $95^{\circ} \mathrm{C}$ for 30 $\mathrm{s} ; 57^{\circ} \mathrm{C}$ for $30 \mathrm{~s}, 72^{\circ} \mathrm{C}$ for $30 \mathrm{~s} ; 72^{\circ} \mathrm{C}$ for $5 \mathrm{~min}$ for the addition of poly-A overhangs and cooled to $4^{\circ} \mathrm{C}$. PCR products were then separated on a $1 \%$ agarose gel and visualized with ethidium bromide using a Fluor-S Multi-Imager densitometer (Bio-Rad Laboratories). The qPCR was performed using ChamQ Universal SYBR qPCR Master Mix (Vazyme, Q711-02), and the PCR program performed as described previously. $\beta$-actin was an interior control. Primers of G/b1/4 and $\beta$-actin are shown in Table 1.

\section{Protein extract and Western blot}

Total protein from sample was extracted with RIPA buffer containing protease inhibitor cocktail (Pierce) and phosphatase inhibitor cocktail (Sigma). Total protein extract (about $30 \mu \mathrm{g}$ ) for each sample was electrophoresed on $12 \%$ polyacrylamide gels (SDS-PAGE). Resolved protein were transferred to Hybond-P membranes (Amersham Pharmacia Biotech), immunoreacted and visualized with the ECL analysis system (Western blot chemiluminescence Reagent Plus, Amersham Pharmacia Biotech). Anti- $\beta$-actin (Sigma), anti-tyrosine phosphorylation antibody (Bio-Techne, MAB16761, 1:2000), anti-CD63 antibody (Abcam, ab217345, 1:2000), anti-EGFP (Abcam, ab6556, 1:2000) and anti-GLB1L4 antiserum (Zhen et al. 2009; 1:5000) were used as primary antibody. The second antibodies $(1: 10,000)$ were the horseradish peroxidase (HRP)-conjugated anti-rabbit (Calbiochem) and anti-mouse IgG (Abcam, ab131368).

\section{Statistical analysis}

The data from the experiments are presented as mean \pm S.D. Data of the groups were compared using independent samples one way ANOVA by SPSS statistics 17.0. The $P$ values less than 
A

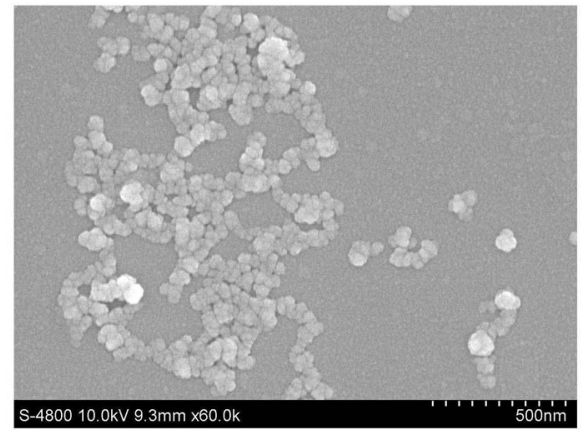

B

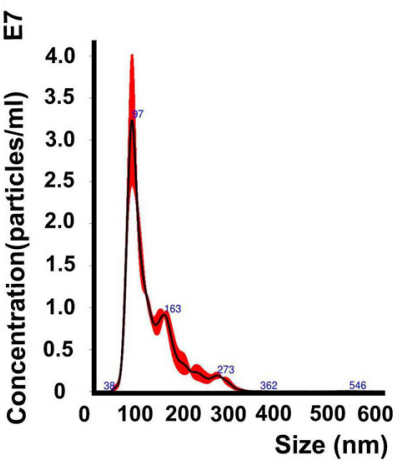

C

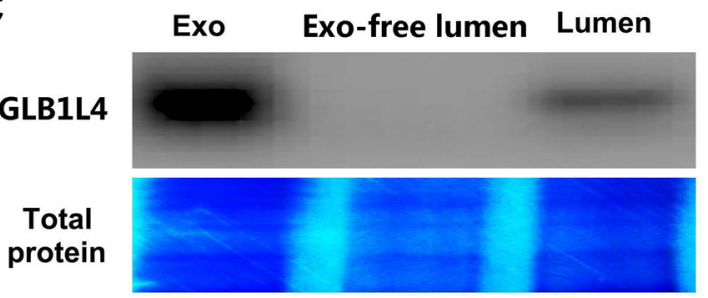

Figure 6 Identification of GLB1L4 protein in epididymal exosomes. (A) The extracellular vesicles from epididymal luminal fluid were observed by S.E.M. (B) Density and sizes of exosomes from epididymal luminal fluid were measured by Nanosight system. (C) GLB1L4 protein in exosomes (Exo), luminal fluid free of exosomes (Exo-free lumen), and whole lumen fluid (Lumen) was analyzed by Western blot.
0.05 were considered statistically significant. Experiments were repeated at least three times and each time in triplicate.

\section{Results}

\section{Analysis of GLB1L4 in the rat epididymis}

The results of RT-PCR pointed out that the G/b1/4 mRNA expressed specifically in the caput epididymis (Fig. 1A), while the GLB1L4 protein distributed in caput, corpus and cauda epididymis in 90-day-old male rats by Western blot analysis (Fig. 1B). Meanwhile, localization of GLB1L4 was further confirmed in caput epididymis and in lumen of corpus and cauda epididymis by immunohistochemistry (Fig. 1C). In addition, it was demonstrated that there existed a low level of GLB1L4 protein of sperm from cauda epididymis by immunofluorescence and Western blot (Fig. 1D and E).

\section{Influence of GLB1L4 knockdown on sperm function}

\section{Lentivirus production and GLB1L4 knockdown efficiency detection}

According to rat Glb1/4 and Egfp gene sequences, stem-loop structure shRNA sequences were designed (shRNA-p1, shRNA-p2 and shRNA-g) (Table 1) and synthetized. The level of G/b1/4 mRNA (Fig. 2A) and GLB1L4 protein (Fig. 2B) were reduced significantly compared with control group (LV-g) when the recombinant lentivirus (Lv-p1 and Lv-p2) were transferred into the PC1 cells overexpressing GLB1L4 protein, respectively. The LV-p1 was more efficient than Lv-p2 (Fig. 2). Therefore, we mainly used the Lv-p1 lentivirus for subsequent studies.

\section{Distribution of lentivirus injected into} rat caput epididymis

The virus solution was rapidly transferred to the rat caput epididymis when $50 \mu \mathrm{L}$ virus (Lv-p1) with Trypan blue (TB) injected into rat caput epididymis (Fig. 3A). On the second day, after the virus was injected into caput epididymis, the green fluorescence of caput epididymis was detected by fluorescence stereoscopy (Fig. 3B). 30 days after injection of viruses, EGFP protein was detected in caput, corpus and cauda and the strong green fluorescence was mainly in caput and cauda epididymis (Fig. 3C, D and E). Further, the level of GLB1L4 protein was downregulated significantly in all section of the epididymis (Fig. 3E). It indicated that the lentivirus could work at least 30 days in rat epididymis.

\section{GLB1L4 expression in different parts in 30 days after injection of lentivirus}

To analyze the expression of GLB1L4 30 days after lentiviral (Lv-p1) injection into rat caput epididymis, tissues of caput epididymis, epididymal lumen liquid and sperm in cauda epididymis were collected, respectively. The results showed that the expression level of GLB1L4 was reduced by at least $50 \%$ in the caput epididymis, epididymal lumen liquid and sperm by Western blot, respectively (Fig. 4).

\section{Influence of GLB1L4 knockdown expression on sperm in vitro capacitation and male fertility}

Motility of sperm in rat cauda epididymis was detected by CASA. Compared with the control (Lv-g), CASA results showed that parameters related to spermatozoa hyperactivity, such as VAP (average path velocity), VSL 

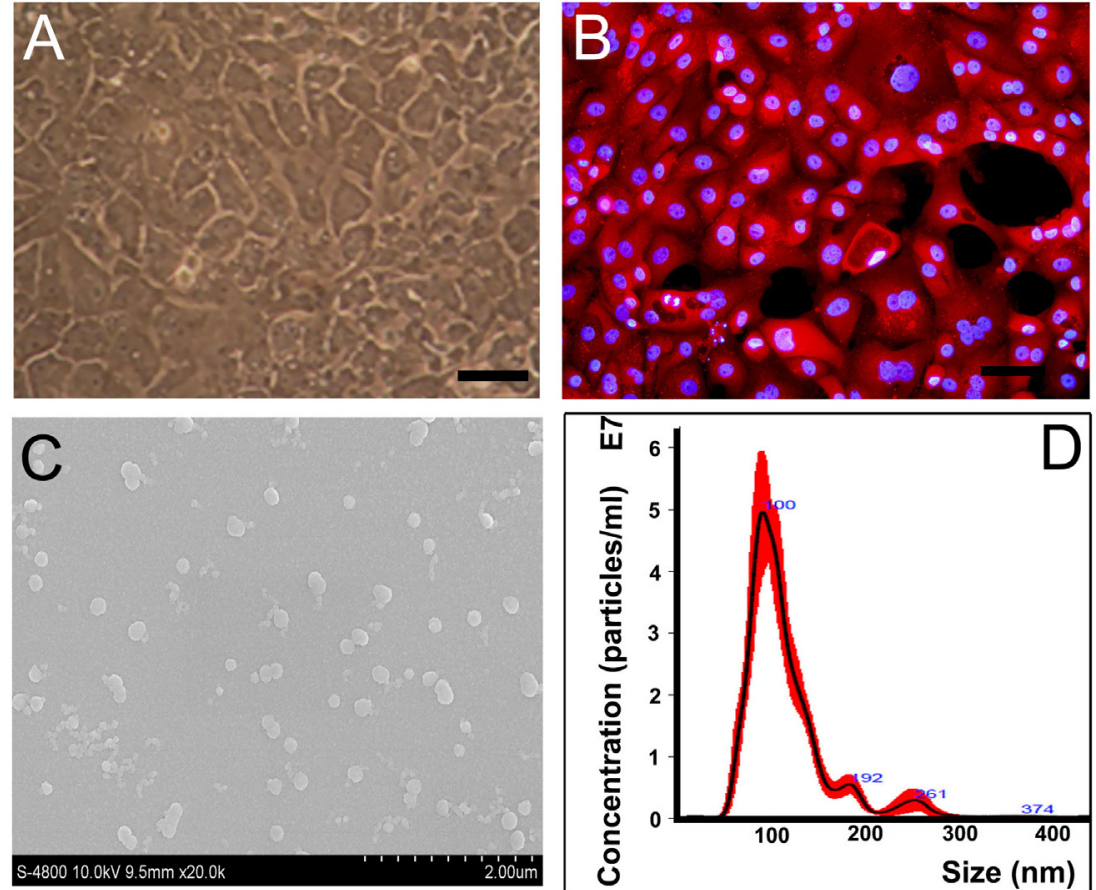

$E$

GLB1L4

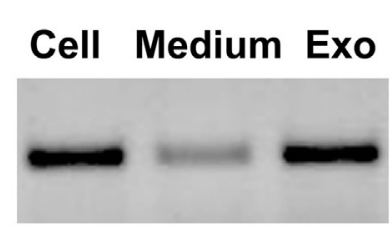

CD63

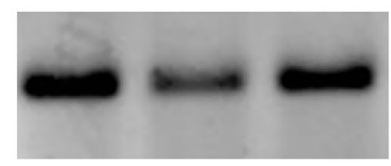

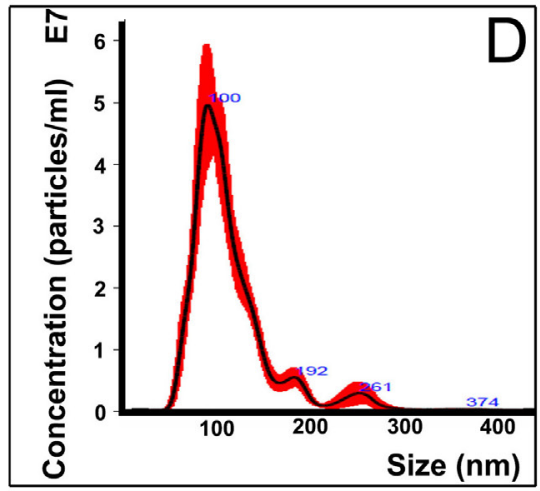

$F$

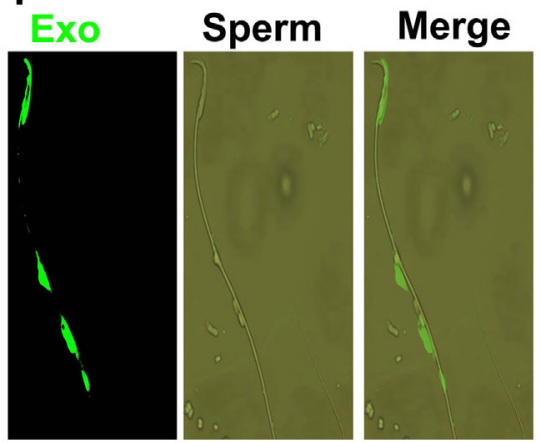

Figure 7 Characterization of the exosomes from the primary epithelial cells of rat caput epididymis and binding to sperm. (A) Morphology of the primary epididymal epithelial cells in the serum-free medium IMDM was displayed. (B) CK8 positive epithelial cells screened out by immunofluorescence. Scale bar: $50 \mu \mathrm{m}$. (C) The exosomes from the epididymal epithelial cells was observed by S.E.M. (D) Density and sizes of exosomes from the epididymal epithelial cells was measured by Nanosight system. (E) Expression of GLB1L4 protein was analyzed by Western blot in the epididymal epithelial cells (cell), the whole medium (medium) and exosomes from the medium (Exo). (F) PKH67 labeled exosomes (PKH67Exo) from the medium band with outer membrane of sperm from cauda epididymis. PKH67-Exo shows green fluorescence. (straight-line velocity), VCL (curvilinear velocity) and ALH (amplitude of lateral head) displacement were significantly decreased in the knockdown group after 3 $\mathrm{h}$ in vitro capacitation $(P<0.05)$, although the indexes was not different before capacitation (Table 2). To examine sperm capacitation, tyrosine phosphorylation of sperm was analyzed during BSA inducting sperm in vitro capacitation by Western blot. On the 30th day after injection of Lv-p1 lentivirus, the level of sperm tyrosine phosphorylation significantly decreased compared with the control (Lv-g) after in vitro capacitation at $3 \mathrm{~h}$ (Fig. 5A).

To analyze the influence of in vivo knockdown expression of GLB1L4 protein on male fertility, the number of fetuses was determined after normal female rats mated with male rats with same lentivirus (Lv-p1 or $\mathrm{Lv}-\mathrm{g}$ ) in bilateral epididymis. After the normal female rats mated with the male rats with same lentivirus (Lv-p1) in bilateral epididymis, the average number of fetuses (12 fetuses) was significantly low compared with control groups (16 fetuses) $(P<0.05)$ (Fig. 5B).

\section{Palmitoylated GLB1L4 protein from caput epididymis transports through exosomes in rat epididymal lumen}

To exploit whether GLB1L4 protein was loaded on epididymal exosomes, the extracellular vesicles from epididymal luminal fluid was isolated by gradient ultracentrifugation. The extracellular vesicles were membranous vesicles with $50-100 \mathrm{~nm}$ in diameter by S.E.M. (Fig. 6A). The average particle size was $97 \mathrm{~nm}$ and the concentration of exosomes in rat epididymal lumen was about $7.4 \times 10^{10}$ particles $/ \mathrm{mL}$ by Nanosight system (Fig. 6B). Western blot showed that this exosome-enriched fraction harbored plenty of GLB1L4 protein, while the GLB1L4 protein seemed to be rare in the exosome-free lumen fraction (Fig. 6C). The results displayed that most GLB1L4 protein from rat 
Table 2 Comparison of effect of Lv-p1 and Lv-g on sperm motility indexes and kinetics parameters in BSA inducing sperm capacitation for $3 \mathrm{~h}$. Results are given as average mean \pm S.D. $(n=3-5)$. Values within columns with different letters represent significant difference $(P<0.05)$.

\begin{tabular}{lcccc}
\hline $\begin{array}{l}\text { Virus } \\
\text { types CT }\end{array}$ & \multicolumn{2}{c}{ Lv-p1 } & \multicolumn{2}{c}{ Lv-g } \\
\cline { 2 - 5 } MS $(\%)$ & $51 \pm 12.4$ & $54 \pm 10.3$ & $50 \pm 6.7$ & $56 \pm 3.6$ \\
PS $(\%)$ & $48.7 \pm 7.6$ & $46.4 \pm 7.4^{\mathrm{A}}$ & $45.5 \pm 5.4$ & $38.3 \pm 5.4^{\mathrm{B}}$ \\
$\mathrm{VAP}(\mu \mathrm{m} / \mathrm{s})$ & $89 \pm 5.2$ & $92 \pm 5.2$ & $92 \pm 7.3$ & $107 \pm 7.3$ \\
$\operatorname{VSL}(\mu \mathrm{m} / \mathrm{s})$ & $86.1 \pm 5.2$ & $92.1 \pm 5.2^{\mathrm{B}}$ & $92 \pm 4.2$ & $108 \pm 4.2^{\mathrm{A}}$ \\
$\operatorname{VCL}(\mu / \mathrm{s})$ & $102 \pm 8.2$ & $113 \pm 5.1^{\mathrm{B}}$ & $112 \pm 10.2$ & $132 \pm 10.2^{\mathrm{A}}$ \\
$\mathrm{ALH}(\mu \mathrm{m})$ & $7.3 \pm 0.4$ & $7.8 \pm 0.4^{\mathrm{B}}$ & $7.6 \pm 0.3$ & $8.6 \pm 0.3^{\mathrm{A}}$ \\
$\mathrm{BCF}(\mathrm{Hz})$ & $19.6 \pm 0.6$ & $19 \pm 0.6^{\mathrm{B}}$ & $20 \pm 0.7$ & $22.3 \pm 1.4^{\mathrm{A}}$ \\
\hline
\end{tabular}

Lv-g refers to sperm collected from the rats injected with the lentivirus Lv-g; Lv-p1 refers to the sperm collected from the rats injected with the lentivirus Lv-g.

ALH, amplitude of lateral head displacement; BCF, beat crossfrequency; CT, capacitation time; MS, number of motile sperm; PS, number of progressive sperm; VAP, average path velocity; VCL, curvilinear velocity; VSL, straight-line velocity.

caput epididymis was loaded onto exosomes in epididymal lumen.

To demonstrate whether the exosomes loaded GLB1 L4 protein comes from caput epididymis, the primary epithelial cells of rat caput epididymis were isolated and cultured in serum-free medium IMEM (Fig. 7A and B) and the extracellular vesicles were separated by gradient ultracentrifugation (Fig. 7C and D). The GLB1L4 protein was detected in exosomes (Fig. 7E) which could be banded with outer membrane of sperm from cauda epididymis (Fig. 7F). It suggested that exosomes loaded GLB1L4 from in vitro culturing caput epithelial cells could bind to sperm in cauda epididymis.

Further, it was predicted that the GLB1L4 protein is a potential palmitoylated protein (Fig. 8A). The 12th cysteine residue (C12) of GLB1L4 protein was predicted to be the most likely palmitoylation site and the 15th cysteine residue $(\mathrm{C} 15)$ as the next highest possible site of palmitoylation.

2-BP, a palmitoylation inhibitor, is widely used to inhibit palmitoylation modification (Webb et al. 2000, Resh 2006, Jennings et al. 2009, Hannoush \& Sun 2010). Compared with the control, the level of GLB1L4 protein in the caput epithelial cells was not significantly changed (Fig. 8C). However, the level of GLB1L4 protein in exosomes from the medium was significant inhibited by 2-BP (Fig. 8C). Especially, the level of palmitoylated GLB1L4 protein in the caput epithelial cells was also significantly reduced when the 2-BP was added into the medium by ABE assay (Fig. 8D).

The preferential palmitoylation of specific cysteine sites is thought to regulate protein membrane binding and subcellular localization (Milligan et al. 1995, Resh 1999). In the PC1 cells transfected with the pcDNA3.1GLB1L4-Wt plasmid (GLB1L4-Wt), the GLB1L4 protein appeared dotted cluster (Fig. 8E). By contrast, the GLB1L4 protein in PC1 cells with mutant GLB1L4 (C12/15S) was more diffuse in whole cells (Fig. 8F). The results indicated that the mutant cysteine at the 12 th and 15th site of GLB1L4 protein significantly affected the localization of GLB1L4 protein in the cells.

\section{Discussion}

The variation of gene expression in different epididymal regions of mammals promotes sperm maturation. Many proteins in caput epididymis involve in the initiative movement of sperm, as well as the functional maintenance (Xu et al. 2010). It has been reported that the G/b 1/4 mRNA was expressed specifically in the caput epididymis of rats and the GLB1L4 protein localized in the epithelial cells of rat caput epididymis (Zhen et al. 2009), which were confirmed in our study. Further, we found that the protein was also present in lumen of cauda epididymis and sperm, although the level of GLB1L4 protein was lower in cauda epididymis and sperm than in caput epididymis. It suggested that GLB1L4 protein from epithelial cells of the caput epididymis might be transported to cauda epididymis in lumen.

The main function of genes in mammalian epididymis is promoting sperm maturation (Zhou et al. 2018). It is very difficult to study the function of epididymis-specific genes in vitro because of the specificity of mammal epididymal structure, while the in vivo conditional knockout is an effective way (Xie et al. 2013, Koch et al. 2015). It was proved that in vivo RNAi could be an effective way to study certain gene (Grillo et al. 2007, Frka et al. 2009, Towne \& Aebischer 2009, Chou et al. 2010). Injection of siRNA into cauda epididymis with electrotransfection had been used to study the function of HongrES1 (Zhou et al. 2008). But it had identified that siRNA can only knockdown target gene expression transiently. ShRNA-lentivirus system is an alternative way which can knockdown target gene expression long-term (Song et al. 2006, Grillo et al. 2007, Harper \& Gonzalez-Alegre 2008, Wang et al. 2008, 2009, Xie et al. 2008, Fan et al. 2014). Lentivirus vectors are potential gene delivery vehicles because of their ability to incorporate into genomic DNA with high efficiency in cells (Yu et al. 2007, Day et al. 2009, van Hooijdonk et al. 2009). So, the lentivirus system was usually used in animal transgenes (Coumoul \& Deng 2006, van Hooijdonk et al. 2009) and gene therapy (Copreni et al. 2004, Nguyen et al. 2005, Oh et al. 2006). In this study, the shRNA-lentivirus was used to knockdown the level of GLB1L4 in vitro or in vivo. The results illustrated that the level of GLB1L4 expression was downregulated significantly after shRNA-lentivirus was injected into the caput epididymis of rats for 1 month (Fig. 4).

Numerous proteins are identified to be involved in sperm maturation in the epididymis (Myles \& Primakoff 1984, Myles et al. 1987, Vreeburg et al. 1990, Hunnicutt et al. 1997, Sipilä et al. 2006). Secretory proteins from 
$12 \quad 12 \quad 15$

MSMWTFLGRPECILCLSSTL

138

.GLWVILCPGPYIGG

347

637

.PVVTSYDYCALITENGD......AHLGH

B
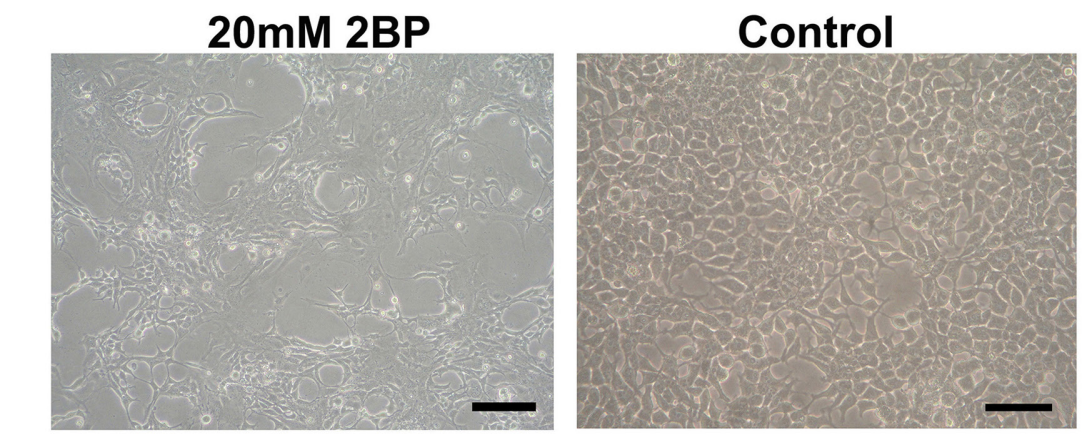

C

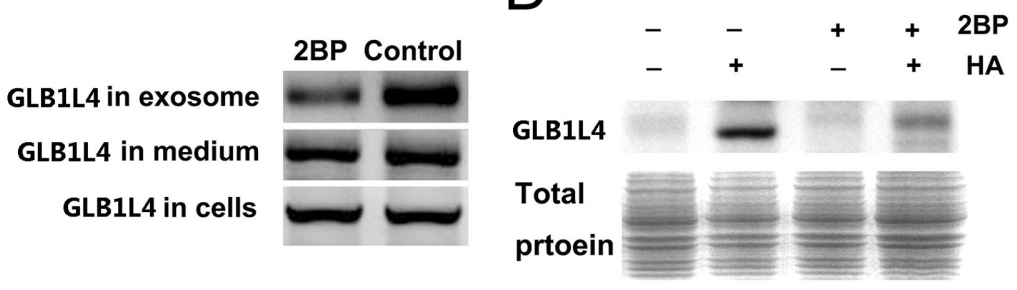

E

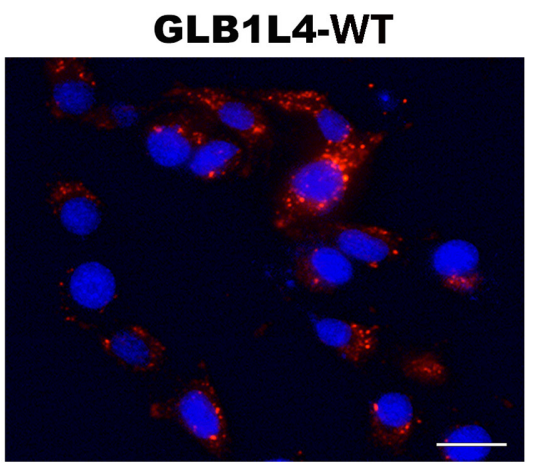

F

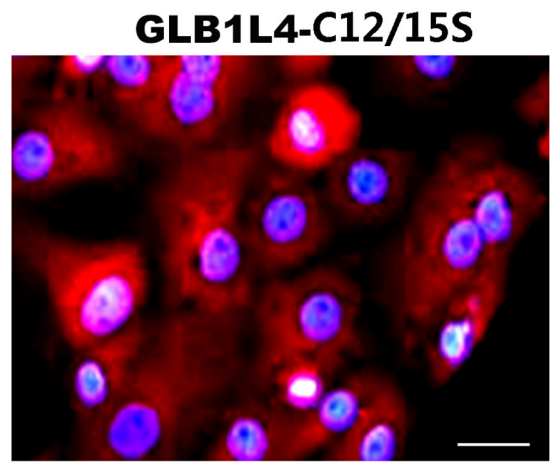

Figure 8 Analysis of the palmitoylated GLB1L4 protein. (A) The potential palmitoylation position of four cysteine residues of rat GLB1L4 protein was predicted by CSS at website http://csspalm.biocuckoo. org/online.php. (B) The morphology of the epithelial cells of caput epididymal was shown when the cells was cultured for $24 \mathrm{~h}$ in the medium with $20 \mathrm{mM} 2-\mathrm{BP}$ or without 2-BP (Control), respectively. Scale bar: 80 $\mu \mathrm{m}$. (C) GLB1L4 protein in cells, whole medium, and exosomes was analyzed by Western blot when the caput epididymal epithelial cells was cultured for $24 \mathrm{~h}$ in the medium with $20 \mathrm{mM}$ 2-BP or without 2-BP (Control), respectively. The level of GLB1L4 protein in the caput epithelial cells was not significantly changed. However, the level of GLB1L4 protein in exosomes from the medium was significant inhibited by $2-B P$. (D) The level of palmitoylated GLB1L4 protein in the caput epithelial cells was also significantly reduced when the 2-BP was added into the medium by $\mathrm{ABE}$ assay. (E) Localization of GLB1L4 protein in PC1 cells transfected pcDNA3.1-GLB1L4-WT plasmid showed clustered. Scale bar: $20 \mu \mathrm{m}$. (F) Localization of GLB1L4 protein in PC1 cells transfected mutant pcDNA3.1-GLB1L4C12/15S plasmid was more diffuse in the PC1 cells. Scale bar: $20 \mu \mathrm{m}$. caput initiate sperm motility (Xu et al. 2010) and the proteins from cauda regulate sperm motility (Dungdung \& Majumder 2003, Das et al. 2010, Ghosh et al. 2018) or affect sperm capacitation (Roberts et al. 2003, Roberts et al. 2006, Ni et al. 2009, Krapf et al. 2012, Saewu et al. 2017). In this study, the sperm hyperactivation indexes (such as VAP, VSL, VCL and ALH) and the level of sperm protein phosphorylation decreased significantly after sperm capacitation of the knockdown GLB1L4 rats was induced by BSA and $\mathrm{Ca}^{2+}$. The average number of fetuses of female rats mated with the GLB1L4 knockdown male rats was significantly low compared with the control group $(P<0.05)$. It was inferred that GLB1L4 protein might regulate hyperactivation of capacitation sperm to maintain the normal physiological function of sperm in epididymis.

As sperm pass through the epididymis, some components of the epididymal fluid bind to the surface 
of the sperm membrane to promote sperm maturation (Young \& Goodman 1982, Cooper 1998, Jones 1998). The epididymosomes (namely exosomes), as cargo carriers, play an important role in transferring secretory proteins in the epididymal fluid onto the sperm surface for sperm maturation (Sullivan 2016, Sullivan \& Mieusset 2016), meanwhile, epididymosomes loading critical molecules are transported from caput to cauda to maintain sperm function during storage of sperm in cauda epididymis (Frenette et al. 2006, Sullivan et al. 2007). In this study, we found that the GLB1L4 is involved in sperm capacitation and the GLB1L4 is released by binding on exosomes in the caput epididymis.

Exosomes, are a kind of nanoparticle with phospholipid bilayer membranous structure, and can selectively load some post-translational modification protein molecules when released from cells (SzaboTaylor et al. 2015, Moreno-Gonzalo et al. 2018). Palmitoyl modification is an important protein modification mode, and the palmitoylation protein can be preferentially selected into exosomes by anchoring to the inner side of the bilayer membrane (Chamberlain \& Shipsto 2015). The cysteine residues at the 12th and 15th sites of GLB1L4 protein molecule might be two key palmitoylation modification sites (Fig. 8A), and the level of palmitoylated GLB1L4 in caput epithelial cells in vitro could be inhibited by 2 -BP (Fig. 8B, C, D and E). Further, the palmitoylated GLB1L4 could be released to the medium from epithelial cells in vitro and GLB1L4 in medium was mainly loaded on exosomes (Fig. 8C). The results indicated that palmitoylated GLB1L4 could be selected into exosomes in epithelial cells of rat caput epididymis and transported to cauda epididymis of rat. In rat cauda epididymis, the exosome could bind with sperm via the affinity of the lipid bilayer of exosome with the sperm membrane, which could result in GLB1L4 being loaded on the exosomes and added into sperm. It implied that GLB1L4 was transferred from epithelia of caput epididymis to sperm in cauda epididymis by exosomes in order to maintain the level of GLB1L4 in sperm.

In summary, GLB1L4 expression was down-regulated by lentivirus injection into the caput epididymis, and the function of GLB1L4 protein could be related to sperm capacitation. Moreover, the palmitoylated GLB1L4 loaded on exosomes could be a main form to regulate the function of sperm in rat epididymis. It will be necessary to further exploit the palmitoyl modified mechanism of GLB1L4 protein and to resolve how the palmitoylated GLB1L4 protein regulates sperm function.

\section{Declaration of interest}

The authors declare that there is no conflict of interest that could be perceived as prejudicing the impartiality of the research reported.

\section{Funding}

This work was supported by the Fund of the Agriculture SciTech Project of Shaanxi Province (No. 2014K01-20-01) and the National Natural Science Foundation China (NSFC) (No. C170104-31172205).

\section{Author contribution statement}

Wuzi Dong was the corresponding author who designed the overall studies. Guofan Peng and Huihui Gao performed bio-statistical analyses. Daqian Dong, Yining Chen and Wuzi Dong performed to inject lentivirus into rat and analyze the morphology of rat. Daqian Dong, Jinmeng Yang and Tianqi Jin performed to Western blot and ABE assay. Heran Cao and Tianqi Jin did the experimental verification. Daqian Dong, Jinmeng Yang and Wuzi Dong wrote and edited the manuscript. Fangxia Yang performed isolation and analysis of exosomes and revised manuscript. All authors discussed the results and commented on the manuscript.

\section{References}

Araki Y, Suzuki K, Matusik RJ, Obinata M \& Orgebin-Crist MC 2002 Immortalized epididymal cell lines from transgenic mice overexpressing temperature-sensitive simian virus 40 large T-antigen gene. Journal of Andrology 23 854-869. (https://doi.org/10.1002/j.1939-4640.2002. tb02344.x)

Björkgren I \& Sipilä P 2019 The impact of epididymal proteins on sperm function. Reproduction 158 R155-R167. (https://doi.org/10.1530/REP18-0589)

Chamberlain LH \& Shipsto MJ 2015 The physiology of protein S-acylation. Physiological Reviews 95 341-376. (https://doi.org/10.1152/ physrev.00032.2014)

Chou MI, Hsieh YF, Wang M, Chang JT, Chang D, Zoual Mi \& Tsay GJ 2010 In vitro and in vivo targeted delivery of IL-10 interfering RNA by JC virus-like particles. Journal of Biomedical Science 17 51. (https://doi. org/10.1186/1423-0127-17-51)

Cooper TG 1998 Interactions between epididymal secretions and spermatozoa. Journal of Reproduction and Fertility: Supplement $\mathbf{5 3}$ 119-136. (https://doi.org/10.1023/A:1022582422932)

Copreni E, Penzo M, Carrabino S \& Conese M 2004 Lentivirus-mediated gene transfer to the respiratory epithelium: a promising approach to gene therapy of cystic fibrosis. Gene Therapy 11 (Supplement 1) S67-S75. (https://doi.org/10.1038/sj.gt.3302372)

Coumoul X \& Deng CX 2006 RNAi in mice: a promising approach to decipher gene functions in vivo. Biochimie 88 637-643. (https://doi. org/10.1016/j.biochi.2005.11.010)

Das S, Saha S, Majumder GC \& Dungdung SR 2010 Purification and characterization of a sperm motility inhibiting factor from caprine epididymal plasma. PLOS ONE 5 e12039. (https://doi.org/10.1371/ journal.pone.0012039)

Day CP, Carter J, Bonomi C, Esposito D, Crise B, Ortiz-Conde B, Hollingshead M \& Merlino G 2009 Lentivirus-mediated bifunctional cell labeling for in vivo melanoma study. Pigment Cell and Melanoma Research 22 283-295. (https://doi.org/10.1111/j.1755-148X.2009.00545.x)

Du J, Wang L, Wang Y, Shen J, Pan C, Meng Y, Yang C, Ji H \& Dong W 2016 Autophagy and apoptosis induced by Chinese giant salamander (Andrias davidianus) Iridovirus (CGSIV). Veterinary Microbiology 195 87-95. (https://doi.org/10.1016/j.vetmic.2016.09.011)

Dungdung SR \& Majumder GC 2003 Isolation and identification of a novel motility-inhibiting factor from goat cauda sperm plasma membrane. Cellular and Molecular Biology 49 413-420.

Dunphy JT \& Linder ME Signalling functions of protein palmitoylation 1998. Biochimica et Biophysica Acta 1436 245-261. (https://doi. org/10.1016/s0005-2760(98)00130-1)

Eickhoff R, Wilhelm B, Renneberg H, Wennemuth G, Bacher M, Linder D, Bucal Ra, Seitz J \& Meinhardt A 2001 Purification and characterization 
of macrophage migration inhibitory factor as a secretory protein from rat epididymis: evidences for alternative release and transfer to spermatozoa. Molecular Medicine 7 27-35. (https://doi.org/10.1007/BF03401836)

Ellerbrock K, Pera I, Hartung S \& Ivell R 1994 Gene expression in the dog epididymis: a model for human epididymal function. International Journal of Andrology 17 314-323. (https://doi.org/10.1111/j.1365-2605.1994. tb01262.x)

Fan X, Rai A, Kambham N, Sung JF, Singh N, Petitt M, Dhal S, Agrawal R, Sutton RE, Druzin ML et al. 2014 Endometrial VEGF induces placental sFLT1 and leads to pregnancy complications. Journal of Clinical Investigation 124 4941-4952. (https://doi.org/10.1172/JCI76864)

Frenette G, Girouard J \& Sullivan R 2006 Comparison between epididymosomes collected in the intraluminal compartment of the bovine caput and cauda epididymidis. Biology of Reproduction 75 885-890. (https://doi.org/10.1095/biolreprod.106.054692)

Frka K, Facchinello N, Del Vecchio C, Carpi A, Curtarello M, Venerando R, Angelin A, Parolin C, Bernardi P, Bonaldo P et al. 2009 Lentiviral mediated RNAi in vivo silencing of Col6a1, a gene with complex tissue specific expression pattern. Journal of Biotechnology 141 8-17. (https:// doi.org/10.1016/j.jbiotec.2009.02.013)

Gao H, Gao Y, Pang W, Pa Cn, Ji H \& Dong W 2018 Iridoviral infection can be reduced by UCHL1-loaded exosomes from the testis of Chinese giant salamanders (Andrias davidianus). Veterinary Microbiology 224 50-57. (https://doi.org/10.1016/j.vetmic.2018.08.025)

Ghosh P, Mukherjee S, Bhoumik A \& Dungdung SR 2018 A novel epididymal quiescence factor inhibits sperm motility by modulating NOS activity and intracellular NO-cGMP pathway. Journal of Cellular Physiology 233 4345-4359. (https://doi.org/10.1002/jcp.26275)

Grillo CA, Tamashiro KL, Piroli GG, Melhorn S, Gass JT, Newsom RJ, Reznikov LR, Smith A, Wilson SP, Sakai RR et al. 2007 Lentivirusmediated downregulation of hypothalamic insulin receptor expression. Physiology and Behavior 92 691-701. (https://doi.org/10.1016/j. physbeh.2007.05.043)

Hannoush RN \& Sun J 2010 The chemical toolbox for monitoring protein fatty acylation and prenylation. Nature Chemical Biology 6 498-506. (https://doi.org/10.1038/nchembio.388)

Harper SQ \& Gonzalez-Alegre P 2008 Lentivirus-mediated RNA interference in mammalian neurons. Methods in Molecular Biology 442 95-112. (https://doi.org/10.1007/978-1-59745-191-8_8)

Hunnicutt GR, Koppel DE \& Myles DG 1997 Analysis of the process of localization of fertilin to the sperm posterior head plasma membrane domain during sperm maturation in the epididymis. Developmental Biology 191 146-159. (https://doi.org/10.1006/dbio. 1997.8700)

Jennings BC, Nadolski MJ, Ling Y, Baker MB, Harrison ML, Deschenes R \& Linder ME 2009 2-Bromopalmitate and 2-(2-hydroxy-5-nitrobenzylidene)-benzo[b]thiophen-3-one inhibit DHHC-mediated palmitoylation in vitro. Journal of Lipid Research 50 233-242. (https:// doi.org/10.1194/jIr.M800270-JLR200)

Jiang H, Zhang X, Chen X, Aramsangtienchai P, Tong Z \& Lin H 2018 Protein lipidation: occurrence, mechanisms, biological functions, and enabling technologies. Chemical Reviews 118 919-988. (https://doi. org/10.1021/acs.chemrev.6b00750)

lones R 1998 Plasma membrane structure and remodelling during sperm maturation in the epididymis. Journal of Reproduction and Fertility: Supplement 53 73-84. (https://doi.org/10.1023/A:1022582422932)

Koch S, Acebron SP, Herbst J, Hatiboglu G \& Niehrs C 2015 Posttranscriptional Wnt signaling governs epididymal sperm maturation. Cell 163 1225-1236. (https://doi.org/10.1016/j.cell.2015.10.029)

Krapf D, Ruan YC, Wertheimer EV, Battistone MA, Pawlak JB, Sanjay A, Pilder SH, Cuasnicu P, Breton S \& Visconti PE 2012 cSrc is necessary for epididymal development and is incorporated into sperm during epididymal transit. Developmental Biology 369 43-53. (https://doi. org/10.1016/j.ydbio.2012.06.017)

Lanyon-Hogg T, Faronato M, Serwa RA \& Tate EW 2017 Dynamic protein acylation: new substrates, mechanisms, and drug targets. Trends in Biochemical Sciences 42 566-581. (https://doi.org/10.1016/j. tibs.2017.04.004)

María-Eugenia Z \& Gisou VDGF 2018 The molecular era of protein S-acylation: spotlight on structure, mechanisms, and dynamics. Critical Reviews in Biochemistry and Molecular Biology 53 420-451. (https:// doi.org/10.1080/10409238.2018.1488804)
Milligan G, Parenti M \& Magee Al 1995 The dynamic role of palmitoylation in signal transduction. Trends in Biochemical Sciences 20 181-187. (https://doi.org/10.1016/s0968-0004(00)89004-0)

Moreno-Gonzalo O, Fernandez-Delgado I \& Sanchez-Madrid F 2018 Posttranslational add-ons mark the path in exosomal protein sorting. Cellular and Molecular Life Sciences 75 1-19. (https://doi.org/10.1007/s00018017-2690-y)

Mühlbauer M, Cheely AW, Yenugu S \& Jobin C 2008 Regulation and functional impact of lipopolysaccharide induced Nod2 gene expression in the murine epididymal epithelial cell line PC1. Immunology $\mathbf{1 2 4}$ 256-264. (https://doi.org/10.1111/j.1365-2567.2007.02763.x)

Myles DG \& Primakoff P 1984 Localized surface antigens of guinea pig sperm migrate to new regions prior to fertilization. Journal of Cell Biology 99 1634-1641. (https://doi.org/10.1083/jcb.99.5.1634)

Myles DG, Koppel DE, Cowan AE, Phelps BM \& Primakoff P 1987 Rearrangement of sperm surface antigens prior to fertilization. Annals of the New York Academy of Sciences 513 262-273. (https://doi. org/10.1111/j.1749-6632.1987.tb25014.x)

Nguyen TH, Bellodi-Privato M, Aubert D, Pichard V, Myara A, Trono D \& Ferry N 2005 Therapeutic lentivirus-mediated neonatal in vivo gene therapy in hyperbilirubinemic Gunn rats. Molecular Therapy 12 852-859. (https://doi.org/10.1016/j.ymthe.2005.06.482)

Ni Y, Zhou Y, Chen WY, Zheng M, Yu J, Li C, Zhang Y \& Shi QX 2009 HongrES1, a cauda epididymis-specific protein, is involved in capacitation of guinea pig sperm. Molecular Reproduction and Development 76 984-993. (https://doi.org/10.1002/mrd.21063)

Oh TK, Li MZ \& Kim ST 2006 Gene therapy for diabetes mellitus in rats by intramuscular injection of lentivirus containing insulin gene. Diabetes Research and Clinical Practice 71 233-240. (https://doi.org/10.1016/j. diabres.2005.08.005)

Percherancier Y, Planchenault T, Valenzuela-Fernandez A, Virelizier JL, Arenzana-Seisdedos F \& Bachelerie F 2001 Palmitoylation-dependent control of degradation, life span, and membrane expression of the CCR5 receptor. Journal of Biological Chemistry 276 31936-31944. (https://doi. org/10.1074/jbc.M104013200)

Resh MD 1999 Fatty acylation of proteins: new insights into membrane targeting of myristoylated and palmitoylated proteins. Biochimica et Biophysica Acta 1451 1-16. (https://doi.org/10.1016/s01674889(99)00075-0)

Resh MD 2006 Use of analogs and inhibitors to study the functional significance of protein palmitoylation. Methods 40 191-197. (https:// doi.org/10.1016/j.ymeth.2006.04.013)

Roberts KP, Wamstad JA, Ensrud KM \& Hamilton DW 2003 Inhibition of capacitation-associated tyrosine phosphorylation signaling in rat sperm by epididymal protein Crisp-1. Biology of Reproduction 69 572-581. (https://doi.org/10.1095/biolreprod.102.013771)

Roberts KP, Ensrud KM, Wooters JL, Nolan MA, Johnston DS \& Hamilton DW 2006 Epididymal secreted protein Crisp-1 and sperm function. Molecular and Cellular Endocrinology 250 122-127. (https:// doi.org/10.1016/j.mce.2005.12.034)

Rodríguez CM, Kirby JL \& Hinton BT 2001 Regulation of gene transcription in the epididymis. Reproduction 122 41-48. (https://doi.org/10.1530/ rep.0.1220041)

Romancino DP, Buffa V, Caruso S, Ferrara I, Raccosta S, Notaro A, Campos Y, Noto R, Martorana V, Cupane A et al. 2018 Palmitoylation is a post-translational modification of Alix regulating the membrane organization of exosome-like small extracellular vesicles. Biochimica et Biophysica Acta: General Subjects 1862 2879-2887. (https://doi. org/10.1016/j.bbagen.2018.09.004)

Saewu A, Kadunganattil S, Raghupathy R, Kongmanas K, Diaz-Astudillo P, Hermo L \& Tanphaichitr N 2017 Clusterin in the mouse epididymis: possible roles in sperm maturation and capacitation. Reproduction 154 867-880. (https://doi.org/10.1530/REP-17-0518)

Shen B, Wu N, Yang JM \& Gould SJ 2011 Protein targeting to exosomes/ microvesicles by plasma membrane anchors. Journal of Biological Chemistry $286 \quad$ 14383-14395. (https://doi.org/10.1074/jbc. M110.208660)

Shibata T, Hadano J, Kawasaki D, Dong X \& Kawabata SI 2017 Drosophila TG-A transglutaminase is secreted via an unconventional Golgiindependent mechanism involving exosomes and two types of fatty acylations. Journal of Biological Chemistry 292 10723-10734. (https:// doi.org/10.1074/jbc.M117.779710) 
Sipilä P, Pujianto DA, Shariatmadari R, Nikkilä J, Lehtoranta $M$, Huhtaniemi IT \& Poutanen M 2006 Differential endocrine regulation of genes enriched in initial segment and distal caput of the mouse epididymis as revealed by genome-wide expression profiling. Biology of Reproduction 75 240-251. (https://doi.org/10.1095/ biolreprod.105.047811)

Snyder EM, Small CL, Bomgardner D, Xu B, Evanoff R, Griswold MD \& Hinton BT 2010 Gene expression in the efferent ducts, epididymis, and vas deferens during embryonic development of the mouse. Developmental Dynamics 239 2479-2491. (https://doi.org/10.1002/ dvdy.22378)

Song Y, Zhang Z, Yu X, Yan M, Zhang X, Gu S, Stuart T, Liu C, Reiser J, Zhang Y et al. 2006 Application of lentivirus-mediated RNAi in studying gene function in mammalian tooth development. Developmental Dynamics 235 1334-1344. (https://doi.org/10.1002/dvdy.20706)

Sullivan R 2016 Epididymosomes: role of extracellular microvesicles in sperm maturation. Frontiers in Bioscience 8 106-114. (https://doi. org/10.2741/s450)

Sullivan R \& Mieusset R 2016 The human epididymis: its function in sperm maturation. Human Reproduction Update 22 574-587. (https://doi. org/10.1093/humupd/dmw015)

Sullivan R, Frenette G \& Girouard J 2007 Epididymosomes are involved in the acquisition of new sperm proteins during epididymal transit. Asian Journal of Andrology 9 483-491. (https://doi.org/10.1111/j.17457262.2007.00281.x)

Szabo-Taylor K, Ryan B, Osteikoetxea X, Szabo TG, Soda Br, Holub M, Nemeth A, Paloczi K, Pallinger É, Winyard P et al. 2015 Oxidative and other posttranslational modifications in extracellular vesicle biology. Seminars in Cell and Developmental Biology 40 8-16. (https://doi. org/10.1016/j.semcdb.2015.02.012)

Towne C \& Aebischer P 2009 Lentiviral and adeno-associated vectorbased therapy for motor neuron disease through RNAi. Methods in Molecular Biology 555 87-108. (https://doi.org/10.1007/978-1-60327295-7_7)

van Hooijdonk LW, Ichwan M, Dijkmans TF, Schouten TG, de Backer MW, Adan RA, Verbeek FJ, Vreugdenhil E \& Fitzsimons CP 2009 Lentivirusmediated transgene delivery to the hippocampus reveals sub-field specific differences in expression. BMC Neuroscience 10 2. (https://doi. org/10.1186/1471-2202-10-2)

Verweij FJ, De Heus C, Kroeze S, Cai H, Kieff E, Piersma SR, Jimenez CR, Middeldorp JM \& Pegtel DM 2015 Exosomal sorting of the viral oncoprotein LMP1 is restrained by TRAF2 association at signalling endosomes. Journal of Extracellular Vesicles 4 26334. (https://doi. org/10.3402/jev.v4.26334)

Vreeburg JT, Holland MK, Cornwall GA \& Orgebin-Crist MC 1990 Secretion and transport of mouse epididymal proteins after injection of 35S-methionine. Biology of Reproduction 43 113-120. (https://doi. org/10.1095/biolreprod43.1.113)

Wan J, Roth AF, Bailey AO \& Davis NG 2007 Palmitoylated proteins: purification and identification. Nature Protocols 2 1573-1584. (https:// doi.org/10.1038/nprot.2007.225)

Wang F, Chen L, Mao ZB, Shao JG, Tan C \& Huang WD 2008 Lentivirusmediated short hairpin RNA targeting the APRIL gene suppresses the growth of pancreatic cancer cells in vitro and in vivo. Oncology Reports 20 135-139. (https://doi.org/10.3892/or.20.1.135)

Wang YH, Wang ZX, Qiu Y, Xiong J, Chen YX, Miao DS \& De W 2009 Lentivirus-mediated RNAi knockdown of insulin-like growth factor-1 receptor inhibits growth, reduces invasion, and enhances radiosensitivity in human osteosarcoma cells. Molecular and Cellular Biochemistry 327 257-266. (https://doi.org/10.1007/s11010-009-0064-y)
Wang Z, Luo J, Wang W, Zhao W \& Lin X 2010 Characterization and culture of isolated primary dairy goat mammary gland epithelial cells. Sheng Wu Gong Cheng Xue Bao 26 1123-1127.

Webb Y, Hermida-Matsumoto L \& Resh MD 2000 Inhibition of protein palmitoylation, raft localization, and $\mathrm{T}$ cell signaling by 2-bromopalmitate and polyunsaturated fatty acids. Journal of Biological Chemistry $275261-270$. (https://doi.org/10.1074/jbc. 275.1.261)

Xie SM, Fang WY, Liu Z, Wang SX, Li X, Liu TF, Xie WB \& Yao KT 2008 Lentivirus-mediated RNAi silencing targeting ABCC2 increasing the sensitivity of a human nasopharyngeal carcinoma cell line against cisplatin. Journal of Translational Medicine 6 55. (https://doi. org/10.1186/1479-5876-6-55)

Xie S, Xu J, Ma W, Liu Q, Han J, Yao G, Huang X \& Zhang Y 2013 Lcn5 promoter directs the region-specific expression of cre recombinase in caput epididymidis of transgenic mice. Biology of Reproduction $\mathbf{8 8} 71$. (https://doi.org/10.1095/biolreprod.112.104034)

Xu W, Zhang X, Chen W, Fok KL, Rowlands DK, Chui YL \& Chan HC 2010 Immunization with Bin1b decreases sperm motility with compromised fertility in rats. Fertility and Sterility 93 0-9580. (https://doi.org/10.1016/j. fertnstert.2008.10.066)

Yang W, Di Vizio D, Kirchner M, Steen H \& Freeman MR 2010 Proteome scale characterization of human S-acylated proteins in lipid raft-enriched and non-raft membranes. Molecular and Cellular Proteomics 9 54-70. (https://doi.org/10.1074/mcp.M800448-MCP200)

Young LG \& Goodman SA 1982 Analysis of lipid and protein components of ejaculated bull sperm surface and seminal plasma. Gamete Research 6 281-291. (https://doi.org/10.1002/mrd.1120060310)

Yu ZY, McKay K, Van Asperen P, Zheng M, Fleming J, Ginn SL, Kizana E, Latham M, Feneley MP, Kirkland PD et al. 2007 Lentivirus vectormediated gene transfer to the developing bronchiolar airway epithelium in the fetal lamb. Journal of Gene Medicine 9 429-439. (https://doi. org/10.1002/jgm.1039)

Zhen W, Li P, He B, Guo J \& Zhang YL 2009 The novel epididymisspecific beta-galactosidase-like gene Glb1l4 is essential in epididymal development and sperm maturation in rats. Biology of Reproduction $\mathbf{8 0}$ 696-706. (https://doi.org/10.1095/biolreprod.108.071589)

Zhou Y, Zheng M, Shi Q, Zhang L, Zhen W, Chen W \& Zhang Y 2008 An epididymis-specific secretory protein HongrES1 critically regulates sperm capacitation and male fertility. PLOS ONE 3 e4106. (https://doi. org/10.1371/journal.pone.0004106)

Zhou W, De Iuliis GN, Dun MD \& Nixon B 2018 Characteristics of the epididymal luminal environment responsible for sperm maturation and storage. Frontiers in Endocrinology 9 59. (https://doi.org/10.3389/ fendo.2018.00059)

Zhu CF, Liu Q, Zhang L, Yuan HX, Zhen W, Zhang JS, Chen ZJ, Hall SH, French FS \& Zhang YL 2007 RNase9, an androgen-dependent member of the RNase A family, is specifically expressed in the rat epididymis. Biology of Reproduction 76 63-73. (https://doi.org/10.1095/ biolreprod.106.054635)

Received 29 July 2020

First decision 20 August 2020

Revised manuscript received 21 November 2020

Accepted 4 December 2020 